\title{
Prognostic and predictive roles of microRNA-411 and its target STK17A in evaluating radiotherapy efficacy and their effects on cell migration and invasion via the p53 signaling pathway in cervical cancer
}

\author{
WEI WEI and CUN LIU \\ Department of Clinical Laboratory, Jining No. 1 People's Hospital, Jining, Shandong 272011, P.R. China \\ Received February 8, 2018; Accepted October 10, 2018
}

DOI: $10.3892 / \mathrm{mmr} .2019 .10826$

\begin{abstract}
Cervical cancer is one of the most common gynecological malignancies worldwide. However, the pathogenesis of cervical cancer remains to be fully elucidated. Increasing evidence shows that microRNAs (miRNAs) may be involved in the pathogenesis of cervical cancer. The present study tested the hypothesis that the overexpression of miRNA (miR)-411 may delay, whereas the overexpression of serine/threonine kinase 17a (STK17A) may contribute to, cervical cancer development and progression through the p53 pathway. Cervical cancer tissues and adjacent normal tissues were obtained from 141 patients with cervical cancer following radiotherapy, with efficacy evaluated. The receiver operating characteristic curve was plotted to show the value of miR-411 and STK17A in predicting the efficacy of radiotherapy. Cox's proportional hazards regression model was utilized for multivariate analysis. A series of inhibitors, mimics or small interfering RNAs against STK17A were introduced to validate the regulatory mechanism of miR-411 in governing STK17A, determined with a luciferase reporter gene assay. The expression of miR-411 and STK17A, and the status of the p53 signaling pathway were evaluated. The colony forming ability, proliferation, migration, invasion and apoptosis of CaSki cells were assessed using a colony formation assay, 3-(4,5-dimethylthiazol-2-yl)-2,5-diphenyltetrazolium bromide assay, Transwell assay and flow cytometry, respectively. miR-411 was upregulated but STK17A was reciprocal in cervical tissues. The overexpression of miR-411 and low expression of STK17A were correlated with high efficacy of radiotherapy. miR-411 and STK17A had predictive value for the efficacy of radiotherapy; miR-411 was the protective factor
\end{abstract}

Correspondence to: Dr Cun Liu, Department of Clinical Laboratory, Jining No. 1 People's Hospital, 6 Jiankang Road, Rencheng, Jining, Shandong 272011, P.R. China

E-mail: liucun_1@126.com

Key words: microRNA-411, STK17A, p53 signaling pathway, cervical cancer, radiotherapy, prognosis and STK17A was a risk factor for prognosis of cervical cancer. Increasing miR-411 activated the p53 signaling pathway and promoted cell apoptosis, but inhibited cell proliferation, invasion and migration. STK17A, an miR-411 target, increased following miR-411 over-expression, whereas the p53 signaling pathway was activated following STK17A inhibition. It was observed that the effect of miR-411 inhibition was lost following STK17A silencing. These findings indicate that the miR-411-mediated direct suppression of STK17A induces apoptosis and suppresses the proliferation, migration and invasion of human cervical cancer cells via the p53 signaling pathway. Additionally, miR-411 and STK17A have predictive value for the efficacy of radiotherapy.

\section{Introduction}

As one of the most frequent types of cancer in women worldwide, cervical cancer is the main cause of mortality from tumors among women, particularly in developing countries (1). There are $>500,000$ patients with cervical cancer and the majority of these (80\%) are in developing countries (2). It is a challenge in China to prevent cervical cancer; surgical excision is primarily used for the treatment of cervical cancer at the early stage and radiotherapy is also an effective way to cure local advanced cervical cancer, particularly to control the disease from a distance (3). Although there has been progress in diagnostic and therapeutic strategies, the survival rate for patients with cervical cancer remains poor (4). Increasing evidence indicates that microRNAs (miRNAs) are implicated in the pathogenesis of cervical cancer, including miR-182 and miR-494 (5-7).

miRNAs can mediate gene expression through inducing mRNA cleavage and suppressing translation (8). miRNAs have significant impacts on cancer and have emerged as important factors in tumorigenesis (9). Certain miRNAs are regarded as oncogenes or tumor suppressor genes, therefore, miRNAs can be used potentially as biomarkers for the diagnosis and prognosis of various types of cancer, including cervical cancer $(10,11)$. For example, miR-150 contributes to cell proliferation in cervical cancer by downregulating forkhead box $\mathrm{O} 4$, and miR-302 inhibits cervical cancer proliferation and invasion by decreasing levels of AKT1 (12). miR-411 
is a member of the miR-379 family, which is located in the miR-379/miR-656 cluster in the DLK-DIO3 region on human chromosome 14 (13). A previous study suggested that miR-379 may act as a tumor suppressor in cervical cancer through directly targeting CRKL, and miR-379 may be considered as an effective strategy for the treatment of cervical cancer (14). Additionally, miR-411 has been reported to be involved in proliferation and differentiation in rhabdomyosarcoma, hepatocellular carcinoma and lung cancer (15-17). A previous study also demonstrated that miR-411 acts as a tumor suppressor in renal cell carcinoma (18). The microRNA.org website resource predicts that the STK17A 3'-untranslated region (UTR) contains miR-411 binding sites. It has been shown that STK17A has low expression in acquired resistance phenotypes of cancer cells, which are resistant to oxaliplatin and 5-fluorouracil (19). The overexpression of STK17A is correlated with lower survival rates in patients with glioma (20). Furthermore, STK17A is a target gene of p53 (21). It has been reported that abnormality of the p53 tumor suppressor gene belongs to the most common molecular events in neoplasia of humans and animals (22). p53 can suppress cancer development by inducing cell-cycle arrest, cell repair/death or anti-angiogenesis (23). In addition, the p53 signaling pathway has been reported to be involved in the pathology of cervical cancer (24-26). The conclusion from the above data is that miR-411 is involved in cervical cancer by mediating STK17A through the p53 axis. The purpose of the present study was to determine the roles of miR-411 and STK17A in cervical cancer radiotherapy and their functions on the cellular processes of cervical cancer cells through the p53 pathway.

\section{Patients and methods}

Study subjects. Cervical cancer tissues and adjacent normal tissues $(5-\mathrm{cm})$ were collected from 141 patients with cervical cancer, who were pathologically diagnosed (27) and underwent cervical biopsy and initial radiotherapy between October 2010 and October 2012 at Jining No. 1 People's Hospital (Jining, China). All specimens were fixed with $10 \%$ formalin and embedded with paraffin. Additionally, $5 \mathrm{ml}$ of venous peripheral blood was collected from fasting patients for polymerase chain reaction (PCR) detection. Among the enrolled patients, there were 82 patients $\geq 45$ years old and 59 patients $<45$ years; 55 patients had stage I cancer according to the FIGO 2012 clinical staging criteria (28), 62 patients had stage II cancer and 24 patients had stage III cancer; 57 patients had a maximum local tumor diameter of $\geq 4 \mathrm{~cm}$ and 84 patients had a maximum local tumor diameter of $<4 \mathrm{~cm}$; 126 patients had squamous cell carcinoma (SCC) and 15 patients had adenocarcinoma (pathological types); 35 patients had lymph node metastasis and 106 patients were without lymph node metastasis; 81 patients were postmenopausal and 60 patients were premenopausal; 96 patients had a hemoglobin level $\geq 110 \mathrm{~g} / \mathrm{L}$ and 45 patients had a level $<110 \mathrm{~g} / \mathrm{L} ; 64$ patients had an SCC antigen level pre-radiotherapy of $\geq 2 \mathrm{ng} / \mathrm{ml}$ and 77 patients had a level of $<2 \mathrm{ng} / \mathrm{ml} ; 33$ patients were treated with four-field conformal radiotherapy, 57 patients with intensity-modulated radiotherapy and 51 patients with pelvic hexagonal field radiotherapy (radiotherapy methods). The study included patients with complete pathological and clinical data and follow-up records. The exclusion criteria were as follows: Patients without complete pathological and clinical data in addition to follow-up records; patients with a history of malignant tumor in other body regions, severe cardiovascular disease, severe liver and kidney dysfunction or other diseases not tolerated radiotherapy. The present study was approved by the Ethics Committee of Jining No. 1 People's Hospital and informed consent was obtained from all patients.

Radiotherapy methods and therapeutic evaluation. External radiotherapy included four-field conformal radiotherapy, intensity-modulated radiotherapy and pelvic hexagonal field radiotherapy. Four-field conformal radiotherapy involved the following: The upper and lower boundary of the radiation field was radiated in the same manner as pelvic field radiation, and 6-MV X-rays were used to irradiate in the box. When irradiation was performed up to 17 times, the anterior and prior field conformal radiotherapy was initiated with an irradiation dose of 45-50 Gy/1.8 Gy each time, 25-28 times every 5-6 weeks. For the intensity-modulated radiotherapy, the upper and lower bounds of the organs at risk were generally located at the upper and lower $2 \mathrm{~cm}$ of the clinical target area and radiotherapy was performed by irradiation with 6-MV X-rays. The prescription dose was 45-50.4 Gy and, following synchronization of lymph node metastasis, the dose was up to 55-65 Gy, 25-28 times/5-6 weeks. The pelvic hexagonal field radiotherapy involved the application of irradiation in the anterior-posterior direction with 6-MV X-rays, and an irradiation dose of 45-50 Gy/1.8 Gy each time, 25-28 times/5-6 weeks.

Each radiotherapy method was repeated every 2-3 weeks. The efficacy was evaluated according to the response evaluation criteria in solid tumors (RECIST) (29) guidelines issued by the World Health Organization in 2000. A complete response (CR) was defined as the disappearance of all target lesions; a partial response (PR) as $\geq 30 \%$ or reduction in the sum of the longest diameters of target lesions compared with the baseline; progressive disease (PD) was defined as $\geq 20 \%$ increase in the sum of the longest diameter of target lesions or the appearance of any new lesions compared with the sum of the shortest diameter recorded since treatment started; stable disease (SD) was between PD and PR. A total of $92 \mathrm{CR}$ and PR cases were recruited into the response group ( $C R+P R)$, and a total of $98 \mathrm{PD}$ and SD cases were included in the non-response group $(\mathrm{PD}+\mathrm{SD})$.

Follow-up. All patients were followed up via outpatient records and telephone interviews for 3 years until October 31st 2015 , and the follow-up rate was $90 \%$. The number of cases of survival was recorded between grouping and end of follow-up, and the 3-year survival rate was equal to the number of cases of survival for $>3$ years accounting for the total cases followed up for $>3$ years. The progression-free survival rate was considered the rate of disease with no progression (no deterioration) in a certain period of time, including CR patients without recurrence in a certain period of time and PR patients or patients without deterioration of disease. The 3-year overall survival and progression-free survival rates were calculated.

Reverse transcription-quantitative PCR (RT-qPCR) analysis. Total RNA was extracted from the tissues, peripheral blood 
Table I. Reverse transcription-quantitative polymerase chain reaction primer sequences.

\begin{tabular}{ll} 
Gene & \multicolumn{1}{c}{ Sequence } \\
\hline miR-411 & F: 5'-GGGGTAGTAGACCGTATAG-3' \\
& R: 5'-TGCGTGTCGTGGAGTC-3' \\
STK17A & F: 5'-GAACACCATGATCCCTTTGG-3' \\
& R: 5'-GTGCCTTTTCCATCCTGAAA-3' \\
p53 & F: 5'-CAGCACATGACGGAGGTTG-3' \\
& R: 5'-TCATCCAAATACTCCACACGC-3' \\
p21 ${ }^{\text {WAF1 }}$ & F: 5'-CACTCCAAACGCCGGCTGATCTTC-3' \\
& R:5'-TGTAGAGCGGGCCTTTGAGGCCCTC-3' \\
TAp63 & F: 5'-GACCTGAGTGACCCCATGTG-3' \\
& R: 5'-TCTGGATGGGGCATGTCTTTGC-3' \\
GAPDH & F: 5'-GGAGCGAGATCCCTCCAAAAT-3' \\
& R: 5'-GGCTGTTGTCATACTTCTCA-3' \\
\hline
\end{tabular}

miR-411, microRNA-411; STK17A, serine/threonine kinase 17a; GAPDH, glyceraldehyde-3-phosphate dehydrogenase; F, forward; $\mathrm{R}$, reverse.

and cells using a TRIzol kit (Invitrogen; Thermo Fisher Scientific, Inc., Waltham, MA, USA), and reverse transcribed into the cDNA template with a PCR amplification instrument. Following this reaction, the cDNA was placed on ice or stored at $-20^{\circ} \mathrm{C}$. The target gene and GAPDH (internal reference) underwent real-time qPCR analysis using the ABI7300 PCR instrument. The reaction mixture was $2 \mathrm{X}$ SYBR-Green qPCR Mix for $10 \mu \mathrm{l}$, forward primers $(10 \mu \mathrm{mol} / \mathrm{L})$ for $1 \mu \mathrm{l}$, revised primers $(10 \mu \mathrm{mol} / \mathrm{l})$ for $1 \mu \mathrm{l}$, cDNA for $1 \mu \mathrm{l}$ and ddwater for $7 \mu \mathrm{l}$. The reaction conditions were as follows: Pre-denaturation at $95^{\circ} \mathrm{C}$ for $10 \mathrm{~min}$, and a total of 40 cycles of denaturation at $95^{\circ} \mathrm{C}$ for $15 \mathrm{sec}$, annealing at $56^{\circ} \mathrm{C}$ for $30 \mathrm{sec}$ and extension at $72^{\circ} \mathrm{C}$ for $32 \mathrm{sec}$. The primers (Table I) for the reaction were synthesized by Applied Biosystems; Thermo Fisher Scientific, Inc.). Each experimental sample underwent experimental verification of complex parallel pumping station with centrifugal pumps and each experiment was repeated three times to obtain the mean value. Then cycle quantification $(\mathrm{Cq})$ value was calculated. The $\mathrm{Cq}$ value refers to the number of PCR cycles when the fluorescence value reaches the threshold, and is a parameter with no unit. GAPDH was used as the internal reference. The $2^{-\Delta \Delta \mathrm{Cq}}$ method (30) was used to determine the ratio of target gene expression in the experiment group to that in the control group, and the formula was as follows: $\Delta \Delta \mathrm{Cq}=$ $\Delta \mathrm{Cq}_{\text {experimentgroup }}-\Delta \mathrm{Cq}_{\text {control group }}$, and $\Delta \mathrm{Cq}=\mathrm{Cq}_{\text {target gene }}-\mathrm{Cq}_{\mathrm{GAPDH}}$.

Western blot analysis. The protein and tissue homogenates of the transfected cells were prepared and transferred into a $1.5-\mathrm{ml}$ centrifuge tube, incubated on ice for $25 \mathrm{~min}$, lysed by ultrasonication for $25 \mathrm{sec}$, and centrifuged at 12,000 x g for $20 \mathrm{~min}$ at $4^{\circ} \mathrm{C}$. The supernatant was collected and transferred into a centrifuge tube and protein concentration was measured using a bicinchoninic acid kit (BCA1-1KT, Sigma-Aldrich; Merck KGaA, Darmstadt, Germany). The sodium dodecyl sulfate-polyacrylamide gel electrophoresis separation gel (8\%) and spacer gel (5\%) were prepared, and the loading quantity of each lane was $50 \mu \mathrm{g}$ total proteins. Following electrophoresis (spacer gel at $80 \mathrm{~V}$ for $30 \mathrm{~min}$, separation gel at $100 \mathrm{~V}$ for $80 \mathrm{~min}$ ), the separated protein was transferred onto polyvinylidene fluoride membranes for incubation at room temperature for $1 \mathrm{~h}$ with the sealing liquid removed. The membranes were incubated with phosphorylated (p)-STK17A antibody (cat. no. 14433-1-AP; Proteintech, Wuhan, China; 1:1,000), p-p21 ${ }^{\mathrm{WAF} 1}$ antibody (cat. no. AP01654PU-N; Origene; 1:10,000), p-p53 antibody (cat. no. MABE518; Merck KGaA; 1:1,000), TAp63 antibody (cat. no. TA311397; Origene; 1:1,000), and GAPDH antibody (cat. no. 10494-1-AP; Proteintech; 1:2,000) at $4^{\circ} \mathrm{C}$ overnight. All the above antibodies were purchased from Abcam (Cambridge, MA, USA). The membranes were washed with Tris-buffered saline with Tween-20 (TBST) times (5 min each time), incubated with the Goat Anti-Mouse, (cat. no. SA00001-1) and Goat Anti-Rabbit, (cat. no. SA00001-2; Proteintech; 1:10,000) for $1 \mathrm{~h}$ at room temperature and washed with TBST three times (each time for $5 \mathrm{~min}$ ). Following scanning and developing, Image Pro Plus 6.0 software (Media Cybernetics, Inc., Silver Spring, MD, USA) was used to analyze the gray values of the protein bands. The experiment was repeated three times.

Luciferase reporter gene assay. The microRNA.org website (http://www.microrna.org)and TargetScanwebsite(http://www. targetscan.org/vert_71/) were used to predict the potential target genes of miR-27a and obtain the sequences of fragments containing binding sites. The psiCheck-2-STK17A-MU plasmid and psiCheck-2-STK17A-WT plasmid were constructed by inserting mutant and wild-type fragments in the 3'-UTR of the STK17A gene into the psiCheck-2 luciferase reporter vector (Promega Corporation, Madison, WI, USA), respectively. The CaSki cervical cancer cells were seeded into a 24-well plate with $1 \times 10^{5}$ cells per well and transfected when the cell density was up to $80 \%$ on the following day. The miR-411 mimic and mimic control were respectively co-transfected with psiCheck-2-STK17A-WT and psiCheck-2-STK17A-MU into CaSki cells using Lipofectamine 2000. After $48 \mathrm{~h}$, the luciferase activity was analyzed using a Dual-Luciferase Reporter Assay system (DLR, Promega Corporation). The target/reference value was taken as the relative luciferase activity and the relative luciferase activity was accessed using a fluorescence instrument (Promega Corporation).

Cell culture and transfection. The HeLa, CaSki, SiHa and C33A cervical cancer cell lines were purchased from the Cell Bank of the Chinese Academy of Sciences (Shanghai, China). The cells were cultured in Dulbecco's modified Eagle's medium (DMEM, Gibco; Thermo Fisher Scientific, Inc.) containing $10 \%$ fetal bovine serum (FBS, Gibco; Thermo Fisher Scientific, Inc.) in a humidified incubator with $5 \% \mathrm{CO}_{2}$ at $37^{\circ} \mathrm{C}$. STK17A small interfering (si)RNA was obtained from Santa Cruz Biotechnology, Inc. (Santa Cruz, CA, USA), and miR-411 mimic, miR-411 inhibitor and negative control (NC) were obtained from Rainbow Chemistry Co., Ltd. (Shanghai, China). Lipofectamine 2000 (Invitrogen; Thermo Fisher Scientific, Inc.) was used to respectively transfect the NC plasmid, miR-411 mimic plasmid, miR-411 inhibitor plasmid, siRNA-STK17A plasmid, miR-411 inhibitor + siRNA-STK17A 
plasmid into the CaSki cell line, which had the highest expression of miR-411. The CaSki cells were assigned into a blank group (without any treatment), and NC, miR-411 mimic, miR-411 inhibitor, siRNA-STK17A, and miR-411 inhibitor + siRNA-STK17A groups. Each group, with the exception of the blank group, was respectively dissolved in Opti-MEM medium, followed by the addition of Lipofectamine 2000 for transfection, according to the manufacturer's protocol. The compounds prepared were directly added into a 6-well plate containing cells and medium, agitated and mixed gently. The cells were incubated in an incubator with $5 \% \mathrm{CO}_{2}$ at $37^{\circ} \mathrm{C}$. After $6 \mathrm{~h}$, the cells were cultured with conventional culture media for the following experiments.

Colony formation assay. The CaSki cells in the logarithmic growth phase were obtained, washed once with phosphate-buffered saline (PBS), and treated with $0.25 \%$ trypsin $(2 \mathrm{ml})$. The cells were centrifuged at $1,000 \mathrm{xg}$ at room temperature for $5 \mathrm{~min}$, collected, and prepared into cell suspension with the cell density adjusted to $2.5 \times 10^{2}$ cells $/ \mathrm{ml}$. The cells were seeded into a 6 -well plate with $2 \mathrm{ml}$ of liquid in each well and cultured in a humidified incubator with $5 \% \mathrm{CO}_{2}$ at $37^{\circ} \mathrm{C}$. After $4 \mathrm{~h}$, cell adhesion was observed. The cells were respectively irradiated with a dose of $0,2,4,6,8$ and $10 \mathrm{~Gy}$, and the irradiation was finished within $2 \mathrm{~h}$. The culture medium was removed and the cells were rinsed twice with PBS, fixed with $500 \mu \mathrm{l}$ of $4 \%$ polyformaldehyde for $2 \mathrm{~h}$ and stained with $0.1 \%$ crystal violet for $3 \mathrm{~h}$. When the dishes had been dried out in air, the clone number was counted under a low power light microscope (magnification, $\mathrm{x} 40$ ). The average number of cloned cells and survival fraction (SF) were calculated. The experiment was repeated three times. The plating efficiency (PE) was calculated as the number of colonies formed as a percentage of the number of viable cells plated at the $0 \mathrm{~Gy}$ dose. Cell survival rate=clone number at a given dose of irradiation/(number of cells at the same dose XPE).

3-(4,5-Dimethylthiazol-2-yl)-2,5-diphenyltetrazolium bromide (MTT) assay. Following $48 \mathrm{~h}$ of transfection, the density of a single cell suspension was adjusted to $5 \times 10^{5}$ cells $/ \mathrm{ml}$, and the cells were seeded into a 96 -well plate with three parallel wells in each group, and cultured in an incubator with $5 \% \mathrm{CO}_{2}$ at $37^{\circ} \mathrm{C}$. Three wells were randomly selected form each group at 12,24 and $48 \mathrm{~h}$. To each well $20 \mu \mathrm{l}$ of $5 \mathrm{mg} / \mathrm{ml}$ MTT fluid (Sigma-Aldrich; Merck KGaA) was added and cultured for $4 \mathrm{~h}$, and the culture medium was discarded. To each well, $150 \mu 1$ of dimethyl sulfoxide was added. The plate was placed on the microplate oscillator to dissolute crystal for $10 \mathrm{~min}$. The optical density (OD) of each well at $490 \mathrm{~nm}$ was measured by an enzyme-linked immunometric meter (Elx800, Bio-Tek Instruments, Inc., Winooski, VT, USA). The experiment was repeated three times. Cell proliferation rate $=($ mean OD of the experiment group)/(mean OD of the control group) $\mathrm{x} 100 \%$.

Transwell assay. The cells in the logarithmic growth phase were obtained to prepare the cell suspension, and seeded into the apical chamber of the Transwell (Corning Costar, Cambridge, MA, USA). RPMI-1640 medium (Gibco; Thermo Fisher Scientific, Inc.) containing $10 \%$ FBS was added into the basolateral chamber. The cells were cultured in an incubator with $5 \% \mathrm{CO}_{2}$ at $37^{\circ} \mathrm{C}$ for $30 \mathrm{~h}$, washed twice with PBS, fixed in $10 \%$ formaldehyde for $15 \mathrm{~min}$ and stained with crystal violet for $20 \mathrm{~min}$. The cells were counted and images were captured at high magnification using an inverted microscope. A total of 5 fields of visions were selected to obtain the mean number of cells.

The transfected cells were cultured for $24 \mathrm{~h}$ and treated with $0.25 \%$ trypsin, and cell density was modulated. The cell suspension was seeded into the Transwell chamber. The apical chamber was coated evenly with Matrigel with all microwells at the bottom of the apical chamber covered. DMEM containing $10 \%$ FBS was added to the bottom of the chamber. After $24 \mathrm{~h}$, the number of cells that invaded through the Matrigel was used to assess the invasive ability.

Flow cytometry. Following transfection for $30 \mathrm{~h}$, the CaSki cells in each group were centrifuged at $1,000 \mathrm{x} \mathrm{g}$ for $5 \mathrm{~min}$ at room temperature and the culture medium was discarded. The cells were then washed once with PBS and incubated with $6 \mu \mathrm{l}$ Annexin V-FITC at room temperature for $15 \mathrm{~min}$ in the dark. Subsequently, $10 \mu \mathrm{l}$ propidium iodide (PI) was added to the cells, followed by immediate analysis with flow cytometry (BD Biosciences, Franklin Lakes, NJ, USA). FlowJo 7.0 software (FlowJo LLC, Ashland, OR, USA) was used to analyze the results, and the experiments were repeated three times. The apoptosis of CaSki cells was analyzed by flow cytometry. The Annevin V (-)/PI (-) cells (left lower lattice) represent normal living cells, the Annexin V (+)/PI (-) cells (right lower lattice) represent apoptotic cells, Annevin (+)/PI (+) (left upper lattice) cells represent necrotic cells, and Annevin V (-)/PI(+) cells (right upper lattice) represent cells with completely impaired membranes during cell digestion and collection.

Statistical analysis. SPSS 21.0 (IBM Corp., Armonk, NY, USA) was used for data analysis. Measurement data are presented as the mean \pm standard deviation. The comparison between two groups was analyzed with a Students t-test and comparison among multiple groups was analyzed using one-way analysis of variance, and checked with Tukey's post hoc test. Enumeration data are presented as a ratio or percentage and were analyzed by $\chi^{2}$ test. The receiver operating characteristic (ROC) curve was drawn to analyze the predictive value of STK17A and miR-411 in the efficacy of radiotherapy. Kaplan-Meier survival analysis and the log-rank test were used to analyze the correlation between the overall survival rate and the progression-free survival rate of patients with cervical cancer. Risk factors for the prognosis of cervical cancer were evaluated using Cox's proportional hazards regression model. $\mathrm{P}<0.05$ was considered to indicate a statistically significant difference.

\section{Results}

Efficacy of radiotherapy is not associated with baseline characteristics. Initially, to understand the factors affecting the efficacy of radiotherapy, the baseline characteristics were compared. As shown in Table II, age, FIGO stage, maximum tumor diameter, pathological type, lymph node metastasis, menopause, hemoglobin level, SCC antigen level pre-radiotherapy and radiotherapy method did not differ significantly between the response group and the non-response group $(\mathrm{P}>0.05)$. 
Table II. Baseline characteristics of cervical cancer between the response and non-response groups.

\begin{tabular}{|c|c|c|c|c|}
\hline & & $\begin{array}{l}\text { Response } \\
\text { group }\end{array}$ & $\begin{array}{l}\text { Non-response } \\
\text { group }\end{array}$ & \\
\hline Group & $\mathrm{N}=141$ & $(\mathrm{~N}=92)$ & $(\mathrm{N}=49)$ & P-value \\
\hline \multicolumn{5}{|l|}{ Age (years) } \\
\hline$\geq 45$ & 82 & 50 & 32 & \multirow[t]{2}{*}{0.209} \\
\hline$<45$ & 59 & 42 & 17 & \\
\hline \multicolumn{5}{|l|}{ FIGO stage } \\
\hline I & 55 & 40 & 15 & \multirow[t]{3}{*}{0.070} \\
\hline II & 62 & 41 & 21 & \\
\hline III & 24 & 11 & 13 & \\
\hline \multicolumn{5}{|l|}{ Maximum tumor diameter $(\mathrm{cm})$} \\
\hline$\geq 4$ & 57 & 36 & 21 & \multirow[t]{2}{*}{0.668} \\
\hline$<4$ & 84 & 56 & 28 & \\
\hline \multicolumn{5}{|l|}{ Pathological type } \\
\hline $\mathrm{SCC}$ & 126 & 81 & 45 & \multirow[t]{2}{*}{0.487} \\
\hline Adenocarcinoma & 15 & 11 & 4 & \\
\hline \multicolumn{5}{|l|}{ Lymph node metastasis } \\
\hline Yes & 35 & 20 & 15 & \multirow[t]{2}{*}{0.246} \\
\hline No & 106 & 72 & 34 & \\
\hline \multicolumn{5}{|l|}{ Menopause } \\
\hline Yes & 81 & 52 & 29 & \multirow[t]{2}{*}{0.761} \\
\hline No & 60 & 40 & 20 & \\
\hline \multicolumn{5}{|l|}{ Hemoglobin level (g/l) } \\
\hline$\geq 110$ & 96 & 64 & 32 & \multirow[t]{2}{*}{0.605} \\
\hline$<110$ & 45 & 28 & 17 & \\
\hline \multicolumn{5}{|c|}{ SCC antigen level pre-radiotherapy (ng/ml) } \\
\hline$\geq 2$ & 64 & 40 & 24 & \multirow[t]{2}{*}{0.532} \\
\hline$<2$ & 77 & 52 & 25 & \\
\hline \multicolumn{5}{|l|}{ Radiotherapy method } \\
\hline Four-field conformal radiotherapy & 33 & 21 & 12 & \multirow[t]{3}{*}{0.080} \\
\hline Intensity-modulated radiotherapy & 57 & 43 & 14 & \\
\hline Pelvic hexagonal field radiotherapy & 51 & 28 & 23 & \\
\hline
\end{tabular}

Data were compared using by $\chi^{2}$ test. SCC, squamous cell carcinoma.

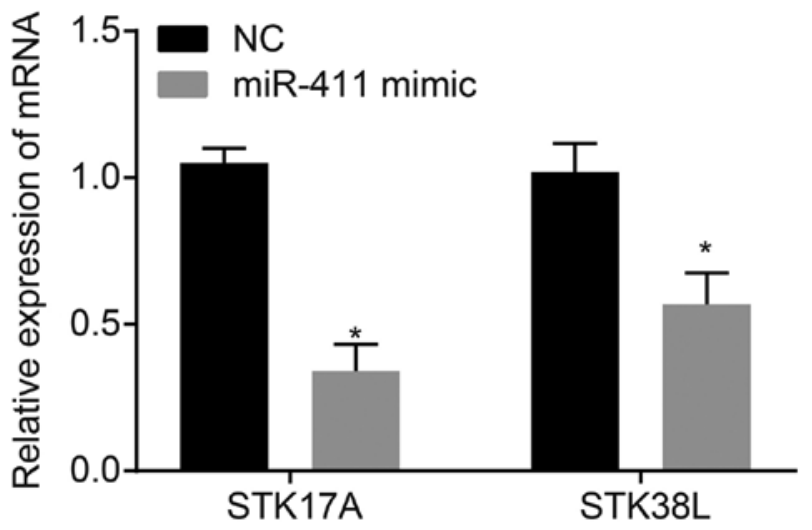

Figure 1. Changes of STK17A are more marked than changes of STK38L following miR-411 mimic treatment. ${ }^{*} \mathrm{P}<0.05$, vs. NC group. STK17A, serine/threonine kinase 17a; STK38L, serine/threonine kinase 38 like; NC, negative control; miR-411, microRNA-411.
Low expression of miR-411 or overexpression of STK17A contributes to cervical cancer and poor efficacy of radiotherapy. A target relationship between miR-411 and serine/threonine kinase 38 like (STK38L) was found via the TargetScan website (http://www.targetscan.org/vert_71/) and microRNA.org. The expression changes of STK17A and STK38L were compared following miR mimic treatment (Fig. 1). The results showed that the changes of STK17A were more marked, therefore, this target gene was selected for further experiments. The expression levels of miR-411 and STK17A in the tissues and peripheral blood were detected to examine their association with radiotherapy efficacy in cervical cancer. As is shown in Fig. 2A, in the cervical cancer tissues, the expression of miR-411 was markedly decreased compared with that in the adjacent normal tissues $(\mathrm{P}<0.05)$; the expression of STK17A was markedly increased compared with that in the adjacent normal tissues $(\mathrm{P}<0.05)$. 

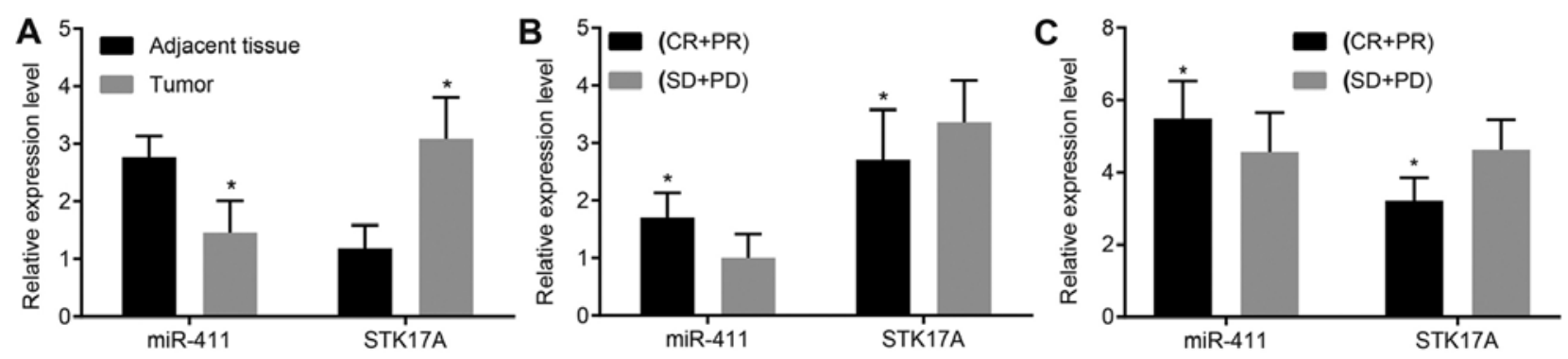

Figure 2. miR-411 is decreased in cervical cancer but increased following response to radiotherapy, with STK17A changing reciprocally. (A) Cervical cancer tissues exhibited decreased expression of miR-411 but increased expression of STK17A compared with the adjacent normal tissues ( $\mathrm{n}=141$, data analyzed by paired t-test), (B) miR-411 was increased and STK17A was decreased in the CR + PR group ( $\mathrm{n}=92)$ compared with the SD + PD group ( $\mathrm{n}=49$ ), data were analyzed by independent t-test. (C) miR-411 was increased and STK17A was decreased in the peripheral blood of the CR + PR group (n-92) compared with the $\mathrm{SD}+\mathrm{PD}$ group $(\mathrm{n}=49)$, data were analyzed by independent $t$-test. ${ }^{*} \mathrm{P}<0.05$, vs. adjacent normal tissues or $\mathrm{SD}+\mathrm{PD}$ group. CR, complete remission; PR, partial remission; PD, progressive disease; SD, stable disease; miR-411, microRNA-411; STK17A, serine/threonine kinase $17 \mathrm{a}$.
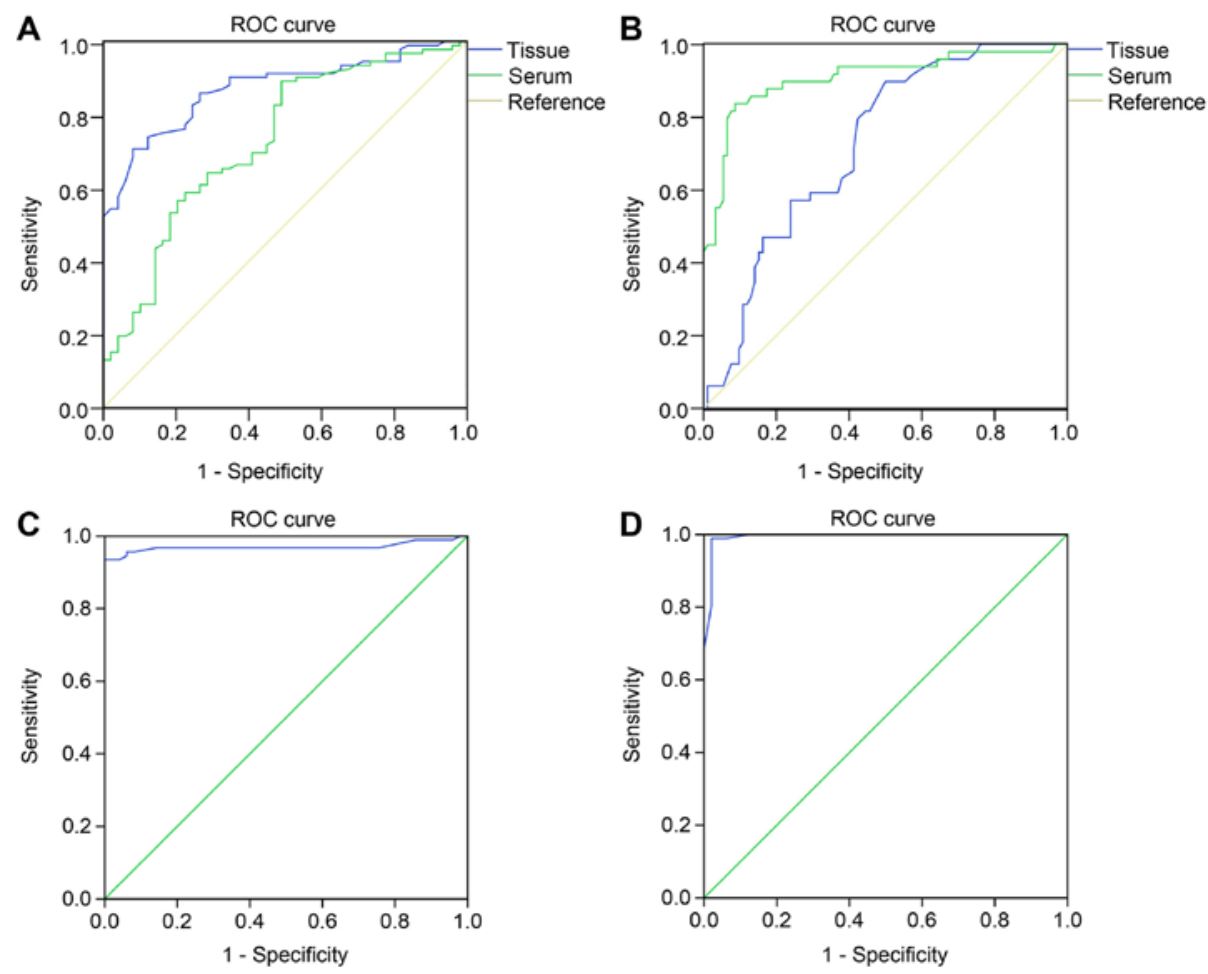

Figure 3. ROC curve indicates good predictive value of the expression of miR-411 and STK17A for radiotherapy efficacy in cervical cancer. (A) Expression of miR-411 showed predictive value for radiotherapy efficacy in cervical cancer. (B) Expression of STK17A had predictive value for radiotherapy efficacy in cervical cancer. (C) Expression of HPV16 had predictive value for radiotherapy efficacy in cervical cancer. (D) Expression of HPV18 had predictive value for radiotherapy efficacy in cervical cancer. ROC, receiver operating characteristic; miR-411, microRNA-411. STK17A, serine/threonine kinase 17a.

As is shown in Fig. 2B, in the response group, the expression of miR-411 was high and increased compared with that in the non-response group $(\mathrm{P}<0.05)$; however, the expression of STK17A was low and reduced significantly compared with that in the non-response group $(\mathrm{P}<0.05)$. As shown in Fig. $2 \mathrm{C}$, the expression of miR-411 in the peripheral blood of the response group of cervical cancer was $5.48 \pm 4.04$ and in the peripheral blood of the non-response group was $4.57 \pm 1.09$; the expression of STK17A in the peripheral blood of the response group of cervical cancer was $3.21 \pm 0.64$ and in the peripheral blood of the non-response group was $4.64 \pm 0.82$ (all $\mathrm{P}<0.001$ ).

Expression of miR-411 and STK17A have predictive value for radiotherapy efficacy in cervical cancer. The expression of miR-411 and STK17A in tissues and peripheral blood was determined to predict radiotherapy efficacy. When the cut-off value was 1.755 in tissues for the expression of miR-411, the area under the ROC curve (AUC) was 0.871 , and the sensitivity and specificity were 70.7 and $91.8 \%$, respectively (95\% confidence interval, 0.814-0.920); when the cut-off value was 4.360 in the peripheral blood, the AUC was 0.729 , and the sensitivity and specificity were 89.1 and $51.0 \%$, respectively (95\% confidence interval, 0.641-0.817), suggesting that miR-411 had good predictive value for radiotherapy efficacy in tissues and peripheral blood in cervical cancer (Fig. 3A). When the cut-off value was 2.605 in tissues for the expression of STK17A, the AUC was 0.723 , and the sensitivity and specificity were 89.8 and $50.0 \%$, respectively (95\% confidence interval, $0.641-0.806$ ); 
Table III. Correlation between the expression levels of miR-411 and STK17A and clinical features of cervical cancer.

\begin{tabular}{|c|c|c|c|c|c|c|c|}
\hline \multirow[b]{2}{*}{ Group } & \multirow[b]{2}{*}{$\mathrm{N}=141$} & \multicolumn{3}{|c|}{ miR-411 expression } & \multicolumn{3}{|c|}{ STK17A expression } \\
\hline & & High/low & $\chi^{2}$ & P-value & High/low & $\chi^{2}$ & P-value \\
\hline \multicolumn{8}{|l|}{ Age (years) } \\
\hline$\geq 45$ & 82 & $39 / 43$ & \multirow[t]{2}{*}{0.148} & \multirow[t]{2}{*}{0.700} & $25 / 57$ & \multirow[t]{2}{*}{1.030} & \multirow[t]{2}{*}{0.310} \\
\hline$<45$ & 59 & $30 / 29$ & & & $13 / 46$ & & \\
\hline \multicolumn{8}{|l|}{ FIGO stage } \\
\hline $\mathrm{I}$ & 55 & $35 / 20$ & \multirow[t]{3}{*}{8.006} & \multirow[t]{3}{*}{0.018} & $12 / 43$ & \multirow[t]{3}{*}{10.890} & \multirow[t]{3}{*}{0.004} \\
\hline II & 62 & $27 / 35$ & & & $13 / 49$ & & \\
\hline III & 24 & $7 / 17$ & & & $13 / 11$ & & \\
\hline \multicolumn{8}{|l|}{ Maximum tumor diameter $(\mathrm{cm})$} \\
\hline$\geq 4$ & 57 & $24 / 33$ & \multirow[t]{2}{*}{1.787} & \multirow[t]{2}{*}{0.171} & $17 / 40$ & \multirow[t]{2}{*}{0.402} & \multirow[t]{2}{*}{0.526} \\
\hline$<4$ & 84 & $45 / 39$ & & & $21 / 63$ & & \\
\hline \multicolumn{8}{|l|}{ Pathological type } \\
\hline $\mathrm{SCC}$ & 126 & $62 / 64$ & \multirow[t]{2}{*}{0.035} & \multirow[t]{2}{*}{0.852} & $34 / 92$ & \multirow[t]{2}{*}{0.001} & \multirow[t]{2}{*}{0.980} \\
\hline Adenocarcinoma & 15 & $7 / 8$ & & & $4 / 11$ & & \\
\hline \multicolumn{8}{|l|}{ Lymph node metastasis } \\
\hline Yes & 35 & $9 / 26$ & \multirow[t]{2}{*}{10.051} & \multirow[t]{2}{*}{0.002} & $12 / 23$ & \multirow[t]{2}{*}{1.272} & \multirow[t]{2}{*}{0.259} \\
\hline No & 106 & $60 / 46$ & & & $26 / 80$ & & \\
\hline \multicolumn{8}{|l|}{ Menopause } \\
\hline Yes & 81 & $39 / 42$ & 0.047 & 0.828 & $21 / 60$ & 0.102 & 0.750 \\
\hline No & 60 & $30 / 30$ & & & $17 / 43$ & & \\
\hline Hemoglobin level (g/l) & & & & & & & \\
\hline$\geq 110$ & 96 & $50 / 46$ & 1.192 & 0.275 & $26 / 70$ & 0.003 & 0.959 \\
\hline$<110$ & 45 & $19 / 26$ & & & $12 / 33$ & & \\
\hline SCC antigen level pre-radiotherapy ( $\mathrm{n}$ & & & & & & & \\
\hline$\geq 2$ & 64 & $32 / 32$ & 0.053 & 0.818 & $18 / 46$ & 0.082 & 0.774 \\
\hline$<2$ & 77 & $37 / 40$ & & & $20 / 57$ & & \\
\hline Radiotherapy method & & & & & & & \\
\hline Four-field conformal radiotherapy & 33 & $9 / 24$ & 8.901 & 0.012 & $11 / 22$ & 12.085 & 0.034 \\
\hline Intensity-modulated radiotherapy & 57 & $34 / 23$ & & & $10 / 47$ & & \\
\hline Pelvic hexagonal field radiotherapy & 51 & $26 / 25$ & & & $17 / 34$ & & \\
\hline
\end{tabular}

SCC, squamous cell carcinoma; miR-411, microRNA-411; STK17A, serine/threonine kinase 17a.

when the cut-off value was 3.890 in the peripheral blood for the expression of STK17A, the AUC was 0.907 , and the sensitivity and specificity were 83.7 and $91.3 \%$, respectively (95\% confidence interval, 0.849-0.966), indicating that STK17A had good predictive value for the efficacy of radiotherapy in tissues and peripheral blood in cervical cancer (Fig. 3B). Furthermore, the expression of HPV16 and HPV18 in tissues were also determined to predict radiotherapy efficacy. In tissues positive for HPV16, the AUC was 0.969, and the sensitivity and specificity were 93.5 and $100.0 \%$, respectively (95\% confidence interval, 0.936-1.000), indicating that HPV16 had good predictive value for the efficacy of radiotherapy in tissues in cervical cancer (Fig. 3C). In tissues positive for HPV18, the AUC was 0.994 , and the sensitivity and specificity were 98.9 and $98.8 \%$, respectively (95\% confidence interval, 0.000-1.000), indicating that HPV18 had good predictive value for the efficacy of radiotherapy in tissues in cervical cancer (Fig. 3D).
miR-411 correlates with FIGO stage, lymph node metastasis and radiotherapy method, and STK17A correlates with FIGO stage and radiotherapy method. The expression levels of miR-411 and STK17A were detected to examine their correlation with the clinical characteristics of cervical cancer. There was no significant association between the expression of miR-411 and age, maximum tumor diameter, pathological type, menopause, hemoglobin level, SCC antigen level pre-radiotherapy or radiotherapy method (all $\mathrm{P}>0.05$ ). However, the expression of miR-411 was significantly lower in patients at FIGO stage II and III, with lymph node metastasis or treated with four-field conformal radiotherapy, compared with patients at FIGO I, without lymph node metastasis or treated with intensity-modulated radiotherapy and pelvic hexagonal field radiotherapy (all $\mathrm{P}<0.05$ ). The expression of STK17A was higher in patients at FIGO stage III and treated with four-field conformal radiotherapy and pelvic hexagonal field radiotherapy, compared with patients at FIGO stage I and II 

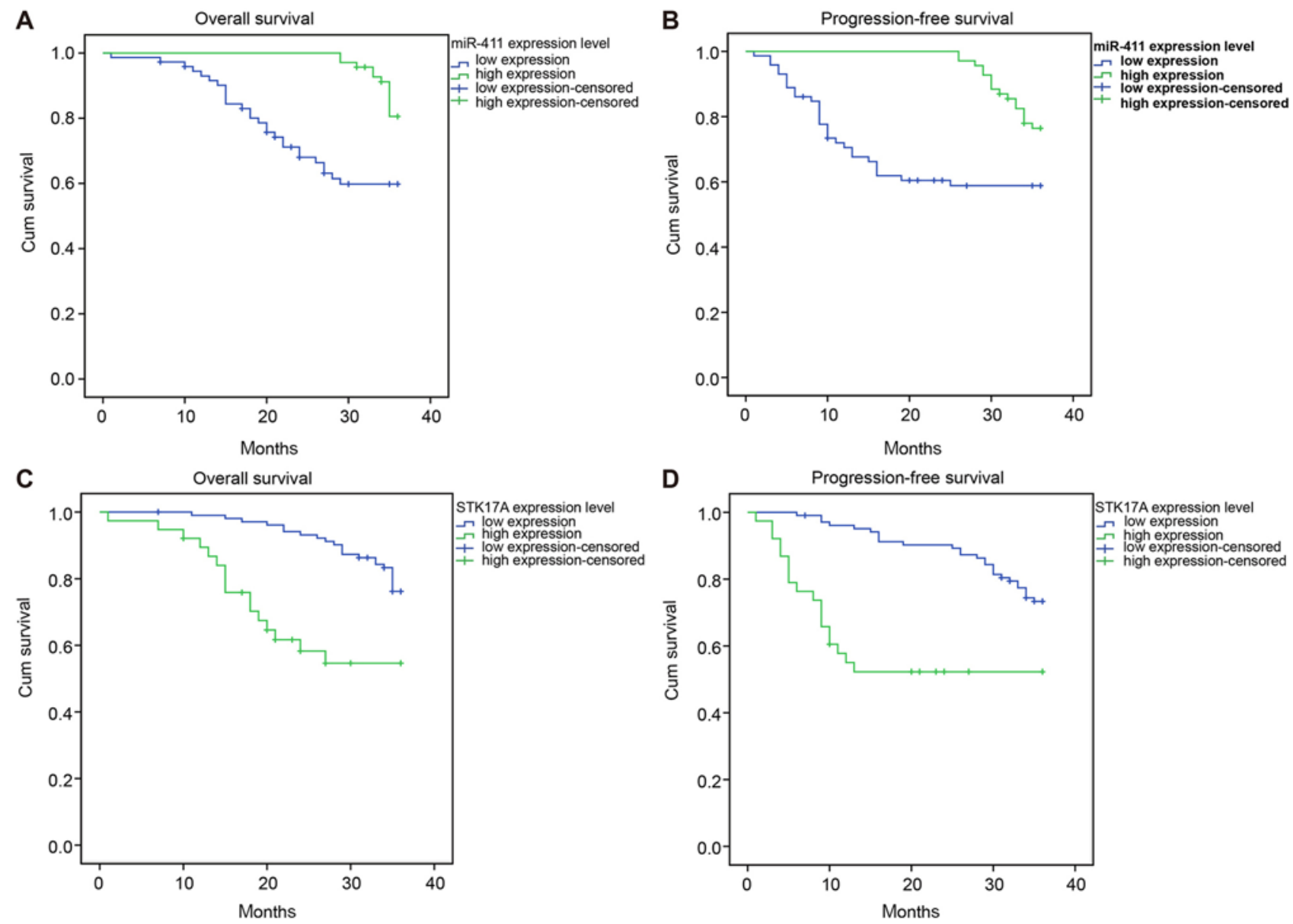

Figure 4. Kaplan-Meier curve indicates that miR-411 is positively correlated and STK17A is negatively with overall survival rate and progression-free survival rate in patients with cervical cancer. (A) Positive correlation between miR-411 and overall survival rate. (B) Positive correlation between miR-411 and progression-free survival rate. (C) Negative correlation between STK17A and overall survival rate. (D) Negative correlation between STK17A and progression-free survival rate; miR-411, microRNA-411; STK17A, serine/threonine kinase 17a.

and treated with intensity-modulated radiotherapy (all $\mathrm{P}<0.05$ ), whereas no difference was found between the expression of STK17A and age, maximum tumor diameter, pathological type, lymph node metastasis, menopause, hemoglobin level, SCC antigen level pre-radiotherapy or radiotherapy method (all $\mathrm{P}>0.05$; Table III).

Low expression of miR-411 $n$ and overexpression of STK17A contribute to poor survival rate. Kaplan-Meier survival analysis and log-rank test were used to analyze the association between overall survival rate, progression-free survival rate and expression levels of miR-411 and STK17A. The patients with a high expression of miR-411 had higher 3-year overall survival and progression-free survival rates, compared with those with a low expression of miR-411 $(\mathrm{P}<0.05)$. The patients with a high expression of STK17A had lower 3-year overall survival and progression-free survival rates, compared with those with a low expression of STK17A $(\mathrm{P}<0.05$; Fig. 4A-D and Table IV). Patients with intensity-modulated radiotherapy and no lymph node metastasis had higher survival rates than those with lymph node metastasis, four-field conformal radiotherapy and pelvic hexagonal field radiotherapy $(\mathrm{P}<0.05)$. No significant association was found between survival rate and age, FIGO stage, maximum tumor diameter, pathological type, menopause, hemoglobin level, SCC antigen level pre-radiotherapy and radiotherapy method (all $\mathrm{P}>0.05$; Table IV).

Risk factors for prognosis include lymph node metastasis, radiotherapy method and expression of STK17A. Cox's regression model was used to analyze the association between the expression of miR-411 and STK17A and the prognosis of patients with cervical cancer, and for the analysis of prognostic risk factors. Cox's proportional hazards regression model suggested that the 3-year survival rate was associated with radiotherapy method and expression levels of miR-411 and STK17A, and 3-year progression-free survival rate was correlated with lymph node metastasis, radiotherapy method and expression levels of miR-411 and STK17A (all $\mathrm{P}<0.05$ ). miR-411 was a protective factor, and lymph node metastasis, radiotherapy method and expression of STK17A were risk factors for the prognosis of patients with cervical cancer (Table V).

Expression of mir-411 is higher and expression of STK17A is lower in cervical cancer cells. The expression levels of miR-411 and STK17A in each cervical cancer cell line were detected to identify the most appropriate cell line for the investigation. As is shown in Fig. 5A, the expression of miR-411 was highest in the C33A cell line, followed by the HeLa and SiHa cell lines, and was lowest in the CaSki cells. As shown in 
Table IV. Correlation between the clinical features of cervical cancer and survival rate in patients.

\begin{tabular}{|c|c|c|c|c|c|c|c|}
\hline Group & $\mathrm{N}=141$ & $\begin{array}{c}\text { 3-year } \\
\text { overall survival } \\
\text { rate }(\%)\end{array}$ & $\chi^{2}$ & P-value & $\begin{array}{l}3 \text { year } \\
\text { progression-free } \\
\text { survival rate }(\%)\end{array}$ & $\chi^{2}$ & P-value \\
\hline \multicolumn{8}{|l|}{ miR-411 } \\
\hline High expression & 69 & $56(81.2)$ & \multirow[t]{2}{*}{11.421} & \multirow[t]{2}{*}{0.001} & $53(76.8)$ & \multirow[t]{2}{*}{9.421} & \multirow[t]{2}{*}{0.002} \\
\hline Low expression & 72 & $45(62.5)$ & & & $43(59.7)$ & & \\
\hline \multicolumn{8}{|l|}{ STK17A } \\
\hline High expression & 38 & $22(57.9)$ & \multirow[t]{2}{*}{13.337} & \multirow[t]{2}{*}{$<0.001$} & $20(52.6)$ & \multirow[t]{2}{*}{14.515} & \multirow[t]{2}{*}{$<0.001$} \\
\hline Low expression & 103 & $79(76.7)$ & & & $76(73.8)$ & & \\
\hline \multicolumn{8}{|l|}{ Age (years) } \\
\hline$\geq 45$ & 82 & $56(68.3)$ & \multirow[t]{2}{*}{1.255} & \multirow[t]{2}{*}{0.263} & $52(63.4)$ & \multirow[t]{2}{*}{1.974} & \multirow[t]{2}{*}{0.160} \\
\hline$<45$ & 59 & $45(76.3)$ & & & $44(74.6)$ & & \\
\hline \multicolumn{8}{|l|}{ FIGO stage } \\
\hline I & 55 & $43(78.2)$ & \multirow[t]{3}{*}{3.544} & \multirow[t]{3}{*}{0.170} & $39(70.9)$ & \multirow[t]{3}{*}{3.625} & \multirow[t]{3}{*}{0.163} \\
\hline II & 62 & $44(71.0)$ & & & $44(71.0)$ & & \\
\hline III & 24 & $14(58.3)$ & & & $13(54.2)$ & & \\
\hline \multicolumn{8}{|l|}{ Maximum tumor diameter $(\mathrm{cm})$} \\
\hline$\geq 4$ & 57 & $37(64.9)$ & \multirow[t]{2}{*}{2.504} & \multirow[t]{2}{*}{0.114} & $35(61.4)$ & \multirow[t]{2}{*}{2.156} & \multirow[t]{2}{*}{0.142} \\
\hline$<4$ & 84 & $64(76.2)$ & & & $61(72.6)$ & & \\
\hline \multicolumn{8}{|l|}{ Pathological type } \\
\hline $\mathrm{SCC}$ & 126 & 89 (70.6) & \multirow[t]{2}{*}{0.499} & 0.480 & $86(68.3)$ & 0.007 & 0.933 \\
\hline Adenocarcinoma & 15 & $12(80.0)$ & & & $10(66.7)$ & & \\
\hline Lymph node metastasis & & & & & & & \\
\hline Yes & 35 & $20(57.1)$ & 4.973 & 0.026 & $18(51.4)$ & 6.721 & 0.010 \\
\hline No & 106 & $81(76.4)$ & & & $78(73.6)$ & & \\
\hline Menopause & & & & & & & \\
\hline Yes & 81 & $56(69.1)$ & 0.417 & 0.519 & $51(63.0)$ & 1.609 & 0.205 \\
\hline No & 60 & $45(75.0)$ & & & $45(75.0)$ & & \\
\hline Hemoglobin level (g/L) & & & & & & & \\
\hline$\geq 110$ & 96 & $69(71.9)$ & 0.076 & 0.783 & $64(66.7)$ & 0.107 & 0.744 \\
\hline$<110$ & 45 & $32(71.1)$ & & & $32(71.1)$ & & \\
\hline $\begin{array}{l}\text { SCC antigen level pre-radiotherapy } \\
(\mathrm{ng} / \mathrm{ml})\end{array}$ & & & & & & & \\
\hline$\geq 2$ & 64 & $45(70.3)$ & 0.190 & 0.663 & $43(67.2)$ & 0.071 & 0.791 \\
\hline$<2$ & 77 & $56(72.7)$ & & & $53(68.8)$ & & \\
\hline Radiotherapy method & & & & & & & \\
\hline Four-field conformal radiotherapy & 33 & $24(72.7)$ & 11.946 & 0.003 & $23(69.7)$ & 6.071 & 0.048 \\
\hline Intensity-modulated radiotherapy & 57 & $48(84.2)$ & & & $44(77.2)$ & & \\
\hline Pelvic hexagonal field radiotherapy & 51 & $29(56.9)$ & & & $29(56.9)$ & & \\
\hline
\end{tabular}

SCC, squamous cell carcinoma; miR-411, microRNA-411; STK17A, serine/threonine kinase 17a.

Fig. 5B, the expression of STK17A was lowest in the C33A cell line, followed by the HeLa and SiHa cell lines, and was highest in the CaSki cells. Therefore, the CaSki cell line was selected to analyze the function of $\mathrm{miR}-411$ in cervical cancer.

miR-411 targets STK17A. The microRNA.org website was used to predict the target relationship between miR-411 and STK17A, and it was found that the STK17A 3'-UTR contained miR-411 binding sites (Fig. 6A). It was found that the miR-411 mimic had no significant effects on the luciferase activity of the Mut-miR-411/STK17A plasmid. There was a marked reduction in the luciferase activity of the Wt-miR-411/STK17A plasmid compared with the Mut-miR-411/STK17A plasmid $(\mathrm{P}<0.05$, Fig. 6B), which suggested that miR-411 directly downregulated STK17A.

Increased radiotherapy dose decreases the proliferation of cervical cancer cells. The proliferation of CaSki cells under 
Table V. Risk factors for prognosis of patients with cervical cancer.

\begin{tabular}{|c|c|c|c|c|c|c|}
\hline \multirow[b]{2}{*}{ Risk factor } & \multicolumn{3}{|c|}{ 3-year overall survival rate } & \multicolumn{3}{|c|}{ 3-year progression-free survival rate } \\
\hline & P-value & EXP & $95 \% \mathrm{CI}$ & P-value & EXP & $95 \% \mathrm{CI}$ \\
\hline miR-411 expression & 0.013 & 0.37 & $0.17-0.81$ & 0.049 & 0.506 & $0.26-0.98$ \\
\hline STK17A expression & 0.018 & 1.9 & $1.18-3.08$ & 0.001 & 3.22 & $1.63-6.36$ \\
\hline FIGO stage & 0.257 & 1.31 & $0.82-2.09$ & 0.452 & 1.2 & $0.75-1.90$ \\
\hline Lymph node metastasis & 0.411 & 1.35 & $0.66-2.73$ & 0.041 & 2.01 & $1.03-3.93$ \\
\hline Radiotherapy method & 0.009 & 1.9 & $1.17-3.08$ & 0.024 & 1.67 & $1.07-2.60$ \\
\hline
\end{tabular}

EXP, Exponential; CI, confidence interval; miR-411, microRNA-411; STK17A, serine/threonine kinase 17a.
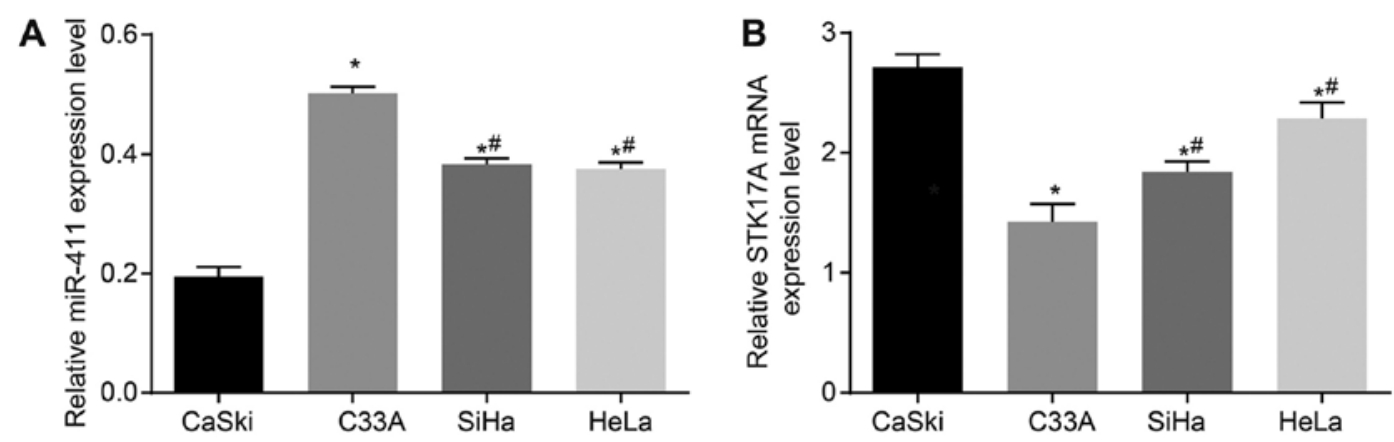

Figure 5. Expression of miR-411 is lowest and STK17A is highest in the CaSki cervical cancer cell line. (A) Expression of miR-411was lowest in the CaSki cervical cancer cell line. (B) Expression of STK17A was highest in the CaSki cervical cancer cell line. ${ }^{*} \mathrm{P}<0.05$, vs. CaSki cell line; ${ }^{\# P}<0.05$, vs. C33A cell line. The experiment was repeated three times, and data were compared by the one-way analysis of variance and analyzed with the Tukey's post hoc test. miR-411, microRNA-411; STK17A, serine/threonine kinase 17a.

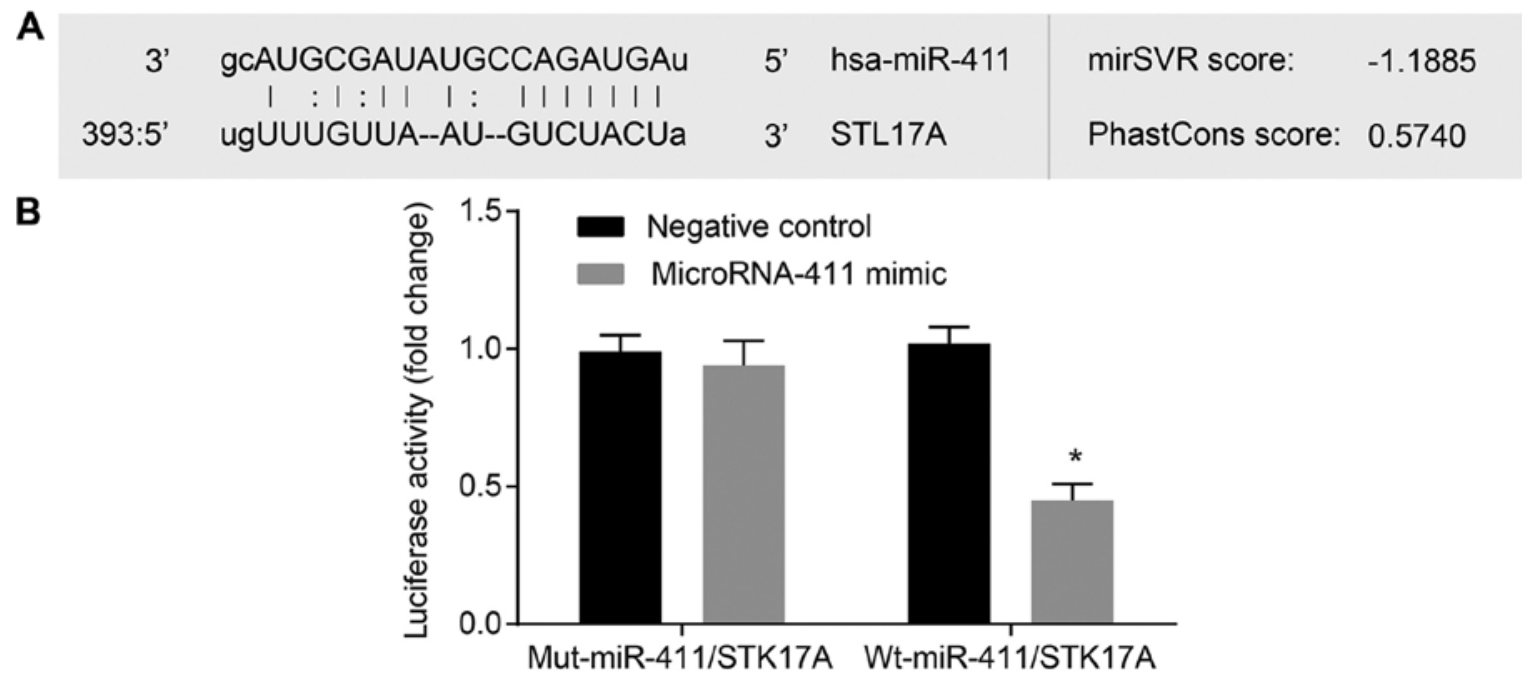

Figure 6. miR-411 directly regulates STK17A. (A) miR-411 was predicted to bind to the STK17A 3'-UTR. (B) Luciferase activity was decreased in the CaSki cells treated by a combination of miR-411 mimic and STK17A-3'UTR-wt, suggesting miR-411 binds to the 3'-UTR of STK17A. The experiment was repeated three times and data were analyzed by independent $t$-test; ${ }^{*} \mathrm{P}<0.05$, vs. negative control group. UTR, untranslated region; miR-411, microRNA-411; STK17A, serine/threonine kinase 17a; wt, wild-type.

different doses of radiotherapy was measured. As is shown in Fig. 7A, the CaSki cell distribution was dense, irregular and flat at the dose of $0 \mathrm{~Gy}$. When the dose was $10 \mathrm{~Gy}$, there was no colony formation, which indicated that different doses of X-ray irradiation affected the colony forming ability and viability of CaSki cells. The clone formation rate and survival rate of the CaSki cells were reduced when the X-ray dose was increased (Fig. 7B and C).

miR-411 suppresses functional STK17A and mediates the p53 signaling pathway in cervical cancer cells. The expression levels of p53 signaling pathway-related genes were detected 

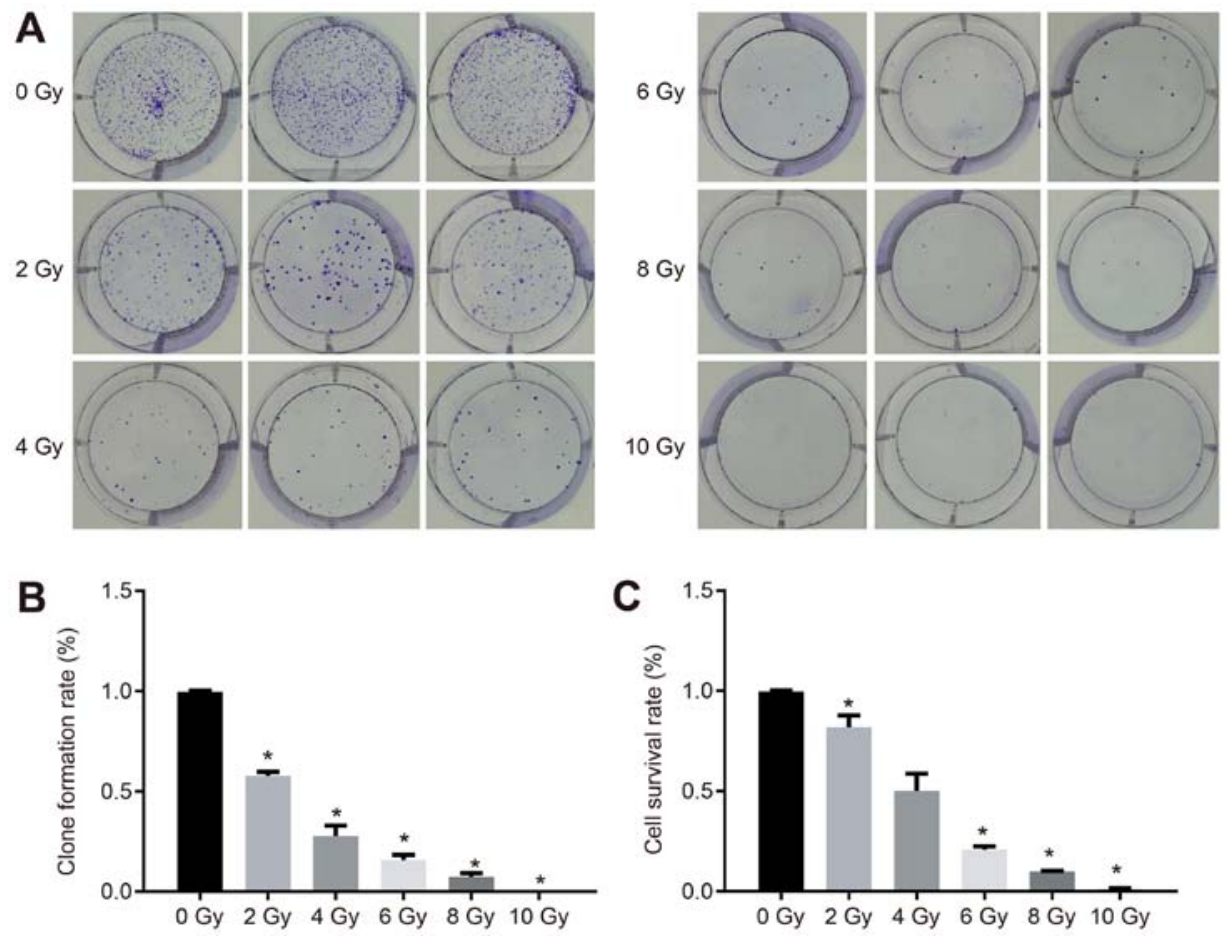

Figure 7. Doses of radiotherapy are negatively correlated with the proliferation of cervical cancer cells. (A) Increased doses of radiotherapy inhibited colony formation. (B) Increased doses of radiotherapy decreased clone formation rate. (C) Increased doses of radiotherapy decreased cell survival rate. The experiment was repeated three times and data were compared by one-way analysis of variance and analyzed with Tukey's post hoc test. " $\mathrm{P}<0.05$, vs. 0 Gy.
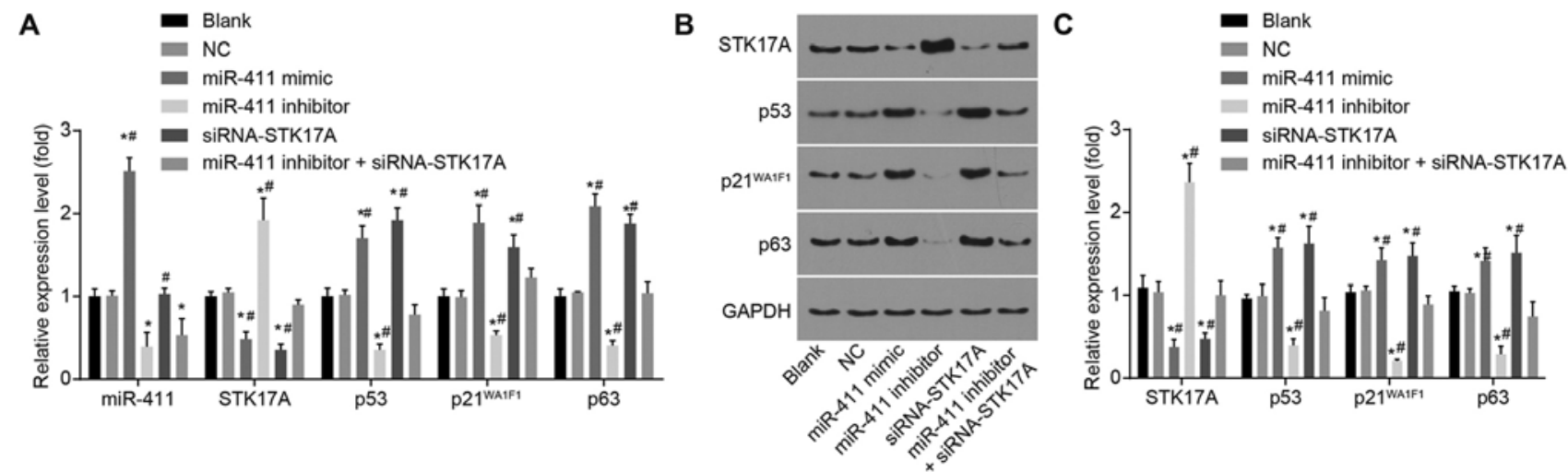

Figure 8. miR-411 activates the p53 signaling pathway and negatively regulates STK17A in cervical cancer cells. (A) Determination by reverse transcription-quantitative polymerase chain reaction analysis demonstrated that ectopic expression of miR-411 and siRNA-mediated knockdown of STK17A decreased the mRNA expression of STK17A, but increased the mRNA expression of $\mathrm{p} 53$, p21 ${ }^{\mathrm{WAF} 1}$ and TAp63; miR-411 inhibitor increased the mRNA expression of STK17A, but decreased the mRNA expression of $\mathrm{p} 53, \mathrm{p} 21^{\mathrm{WAF} 1}$ and TAp63. (B) Determination by western blot analysis and (C) quantification demonstrated that ectopic expression of miR-411 and siRNA-mediated knockdown of STK17A decreased the protein expression of STK17A, but increased the protein expression of $\mathrm{p} 53, \mathrm{p} 21^{\mathrm{WAF} 1}$ and TAp63; miR-411 inhibitor increased the protein expression of STK17A, but decreased the protein expression of p53, p21 ${ }^{\mathrm{WAF} 1}$ and TAp63. ${ }^{*} \mathrm{P}<0.05$, vs. NC group; ${ }^{*} \mathrm{P}<0.05$, vs. miR-411 inhibitor + siRNA-STK17A group. The experiment was repeated three times and data were compared by one-way analysis of variance and analyzed by Tukey's post hoc test. NC, negative control; miR-411, microRNA-411; STK17A, serine/threonine kinase 17a; siRNA, small interfering RNA.

by RT-qPCR and western blot analyses to examine the role of miR-411 in the p53 signaling pathway. Following CaSki cell line transfection, compared with the NC group, the expression of miR-411 was markedly increased in the miR-411 mimic group and markedly decreased in the miR-411 inhibitor and miR-411 inhibitor + siRNA-STK17A groups (all $\mathrm{P}<0.05)$. Compared with the NC group, the mRNA and protein expression levels of STK17A were decreased, but the mRNA and protein expression levels of p53, p $21^{\mathrm{WAF} 1}$ and TAp63 were increased in the miR-411 mimic and siRNA-STK17A groups (all $\mathrm{P}<0.05)$. The mRNA and protein expression levels of STK17A were elevated, whereas the mRNA and protein expression of $\mathrm{p} 53, \mathrm{p} 21^{\mathrm{WAF} 1}$ and TAp63 were reduced in the miR-411 inhibitor group (all $\mathrm{P}<0.05$ ). Compared with the miR-411 inhibitor group, the mRNA and protein expression levels of STK17A were lower in the miR-411 inhibitor + siRNA-STK17A group, whereas the mRNA and protein expression levels of p53, p21 ${ }^{\mathrm{WAF} 1}$ and TAp63 were higher (all $\mathrm{P}<0.05)$. The mRNA and protein expression levels of STK17A were lower, whereas those of p53, p21 ${ }^{\mathrm{WAF} 1}$ and 
TAp63 were higher in the siRNA-STK17A group than in the miR-411 inhibitor + siRNA-STK17A group (all $\mathrm{P}<0.05$ ). No significant differences were observed in the expression of miR-411, or the mRNA and protein expression levels of STK17A, p53, p21WAF1 and TAp63 between the NC group and blank group (all $\mathrm{P}>0.05$ ). In general, the inhibition of miR-411 decreased the expression of $\mathrm{p} 53, \mathrm{p} 21^{\mathrm{WAF} 1}$ and TAp63 through upregulating STK17A (Fig. 8A-C).

STK17A is responsible for the inhibitory effect of miR-411 on the proliferation of cervical cancer cells. In order to investigate the effect of miR-411 and STK17A on cell proliferation of cervical cancer, an MTT assay was performed. As is shown in Fig. 9A-D, compared with the $\mathrm{NC}$ group, the cell viability of the miR-411 inhibitor group exhibited a sharp increase, whereas the rates in the miR-411 mimic group and siRNA-STK17A group exhibited a sharp decrease (all $\mathrm{P}<0.05)$. The cell viability in the $\mathrm{NC}$ group and miR-411 inhibitor + siRNA-STK17A group were almost the same as that in the blank group (all $\mathrm{P}>0.05$ ), indicating that the increase of miR-411 and decrease of STK17A inhibited the proliferation of cervical cancer cells.

STK17A is responsible for the inhibitory effect of miR-411 on cervical cancer cell migration and invasion. In order to investigate the effects of miR-411 and STK17A on cell migration and invasion of cervical cancer, a Transwell assay was performed. CaSki cell migration and invasion in the $\mathrm{NC}$ group did not differ significantly from that in the blank group (both $\mathrm{P}>0.05$ ). CaSki cell migration and invasion were reduced following transfection with the miR-411 mimic or siRNA-STK17A, but enhanced following transfection with miR-411 inhibitor, compared with the NC group (all $\mathrm{P}<0.05$ ). CaSki cell migration and invasion were reduced following transfection with miR-411 inhibitor + siRNA-STK17A, compared with the miR-411 inhibitor group (both $\mathrm{P}<0.05$ ). This indicated that the inhibition of miR-411 or STK17A inhibited the migration and invasion of CaSki cells (Fig. 10A-D).

STK17A is responsible for the promoting effect of miR-411 on cervical cancer cell apoptosis. To further investigate the effect of miR-411 and STK17A on the apoptosis of cervical cancer cells, a Transwell assay was performed. As is shown in Fig. 11A and $\mathrm{B}$, the apoptotic rate of CaSki cells was decreased following transfection with the miR-411 inhibitor compared with that in the $\mathrm{NC}$ group, but the rate was increased following transfection with the miR-411 mimic or siRNA-STK17A (both $\mathrm{P}<0.05$ ). Compared with the miR-411 inhibitor group, the apoptotic rate was increased in the miR-411 inhibitor + siRNA-STK17A group, however, the rate remained lower in the miR-411 inhibitor group than in the siRNA-STK17A group (all $\mathrm{P}<0.05$ ). The apoptotic rate in the NC group did not differ significantly to that in the blank group $(\mathrm{P}>0.05)$. These results suggested that the apoptotic rate of CaSki cells was increased by the increase of miR-411 or decrease of STK17A.

\section{Discussion}

Cervical cancer, one of the most common types of cancer in women worldwide, requires improvements in therapy due to

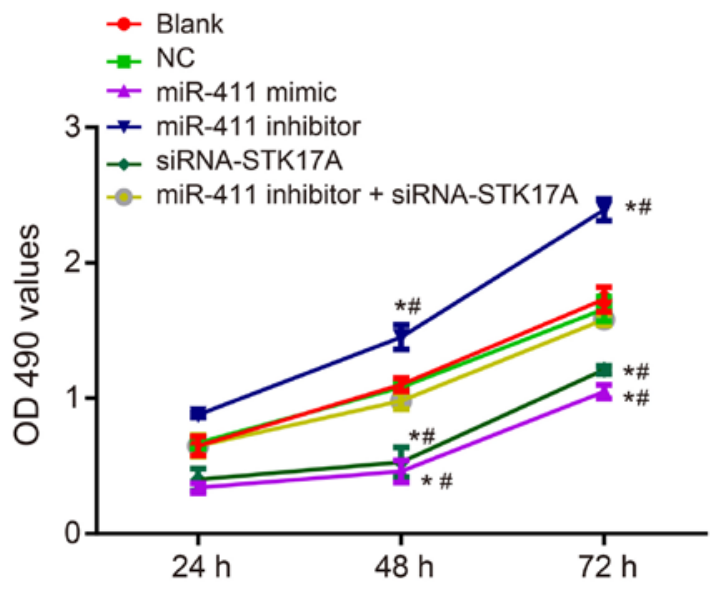

Figure 9. 3-(4, 5-dimethylthiazol-2-yl)-2, 5-diphenyltetrazolium bromide assay suggests that miR-411 inhibits cervical cancer cell proliferation through the STK17A-dependent p53 signaling pathway. The experiment was repeated three times, and data were compared by one-way analysis of variance and analyzed by Tukey's post hoc test. ${ }^{*} \mathrm{P}<0.05$ vs. NC; ${ }^{\text {}} \mathrm{P}<0.05$ vs. miR-411 inhibitor + siRNA-STK17A. NC, negative control; miR-411, microRNA-411; STK17A, serine/threonine kinase 17a; siRNA, small interfering RNA; OD, optical density.

the lack of defined biomarkers and targets for the development of this disease (31). In terms of etiology, the factors influencing cervical cancer are various, including nutritional factors, smoking, reproductive factors, genetic factors and sex factors (2). The objective of the present study was to examine the correlation of miR-411 and STK17A with radiotherapy efficacy and prognosis of cervical cancer. The main conclusion of the study was that the upregulation of miR-411 can inhibit the expression of STK17A, activate the p53 signaling pathway, suppress proliferation, migration and invasion, and promote the apoptosis of cervical cancer cells.

Firstly, it was found that, compared with adjacent normal tissues, miR-411 exhibited decreased expression whereas STK17A exhibited increased expression in cervical cancer tissues. It is reported that $>50 \%$ of miRNAs are present in fragile sites and cancer-associated genomic regions, which indicates that miRNAs are important in cancer formation and are significant regulators for diverse types of cancer, including cervical cancer $(26,32)$. miR-411 has also been demonstrated to be downregulated in breast cancer (33) and in osteoarthritis cartilage (34). STK17A, a novel target gene of $\mathrm{p} 53$, has been found to be a factor affecting the functions of cancer cells and exhibits increased expression in cancer cells $(21,35,36)$. P53 has been revealed to be a suppressive factor in cervical cancer and its activation can inhibit the proliferation, migration and invasion of cervical cancer cells (37). It has been observed that the expression of miR-411 had a close association with FIGO stage and lymph node metastasis; two previous studies have demonstrated that miRNAs have a correlation with FIGO stage and that miR-411 is associated with lymph node metastasis in patients with breast cancer $(33,38)$. Furthermore, in the present study, it was found that the overexpression of miR-411 and low expression of STK17A were correlated with the high efficacy of radiotherapy and favorable prognosis. miR- 411 has been identified as a prognostic biomarker and serves as a tumor promotor for non-small cell lung cancer (39). In a study by 
A
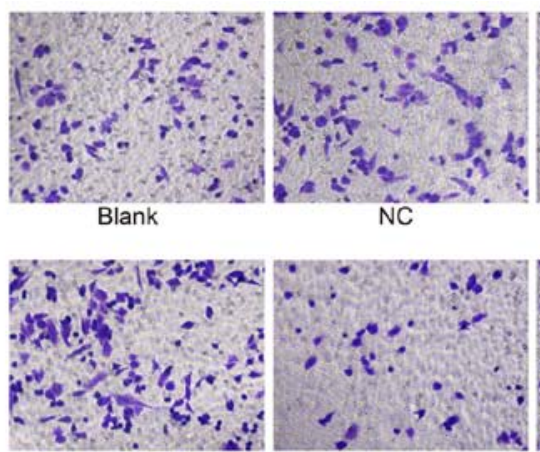

miR-411 inhibitor

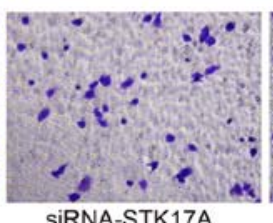

siRNA-STK17A

C

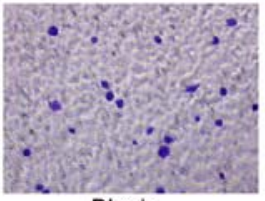
Blank

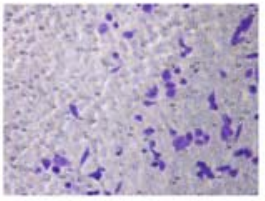

miR-411 inhibitor

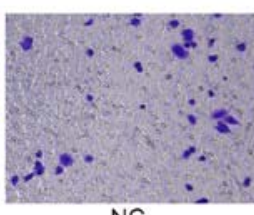
NC

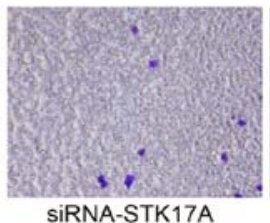

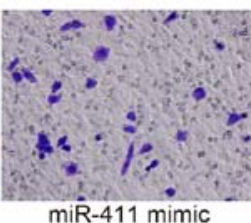

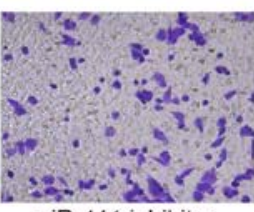

miR-411 inhibitor

+ siRNA-STK17A
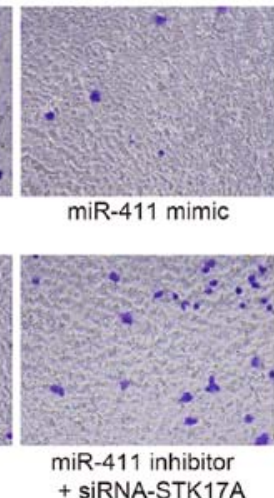
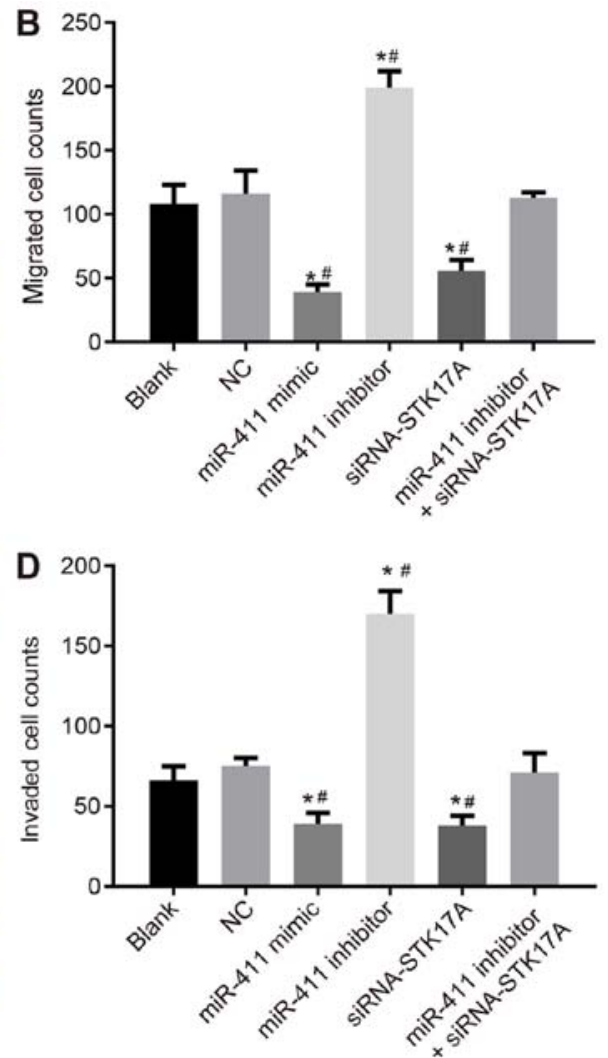

Figure 10. Transwell assay shows that miR-411 suppresses cervical cancer cell migration and invasion through the STK17A-dependent p53 signaling pathway. (A) Under the inverted microscope (magnification, x200), the number of migrated cells reduced following upregulation of miR-411 or siRNA-mediated knockdown of STK17A, but increased following inhibitor-mediated knockdown of miR-411. (B) Numbers of migrated cells are indicated in a representative histogram. (C) Under the inverted microscope (magnification, $\mathrm{x} 200$ ), the number of cells in the basolateral chamber decreased following upregulation of miR-411 or siRNA-mediated knockdown of STK17A, but increased following inhibitor-mediated knockdown of miR-411. (D) Numbers of cells passing through the Matrigel from the apical chamber to the basolateral chamber are indicated in a representative histogram. ${ }^{*} \mathrm{P}<0.05$, vs. $\mathrm{NC}$ group; ${ }^{*} \mathrm{P}<0.05$, vs. miR-411 inhibitor + siRNA-STK17A group. The experiment was repeated three times and data were compared by one-way analysis of variance and analyzed by Tukey's post hoc test. NC, negative control; miR-411, microRNA-411; STK17A, serine/threonine kinase 17a; siRNA, small interfering RNA.
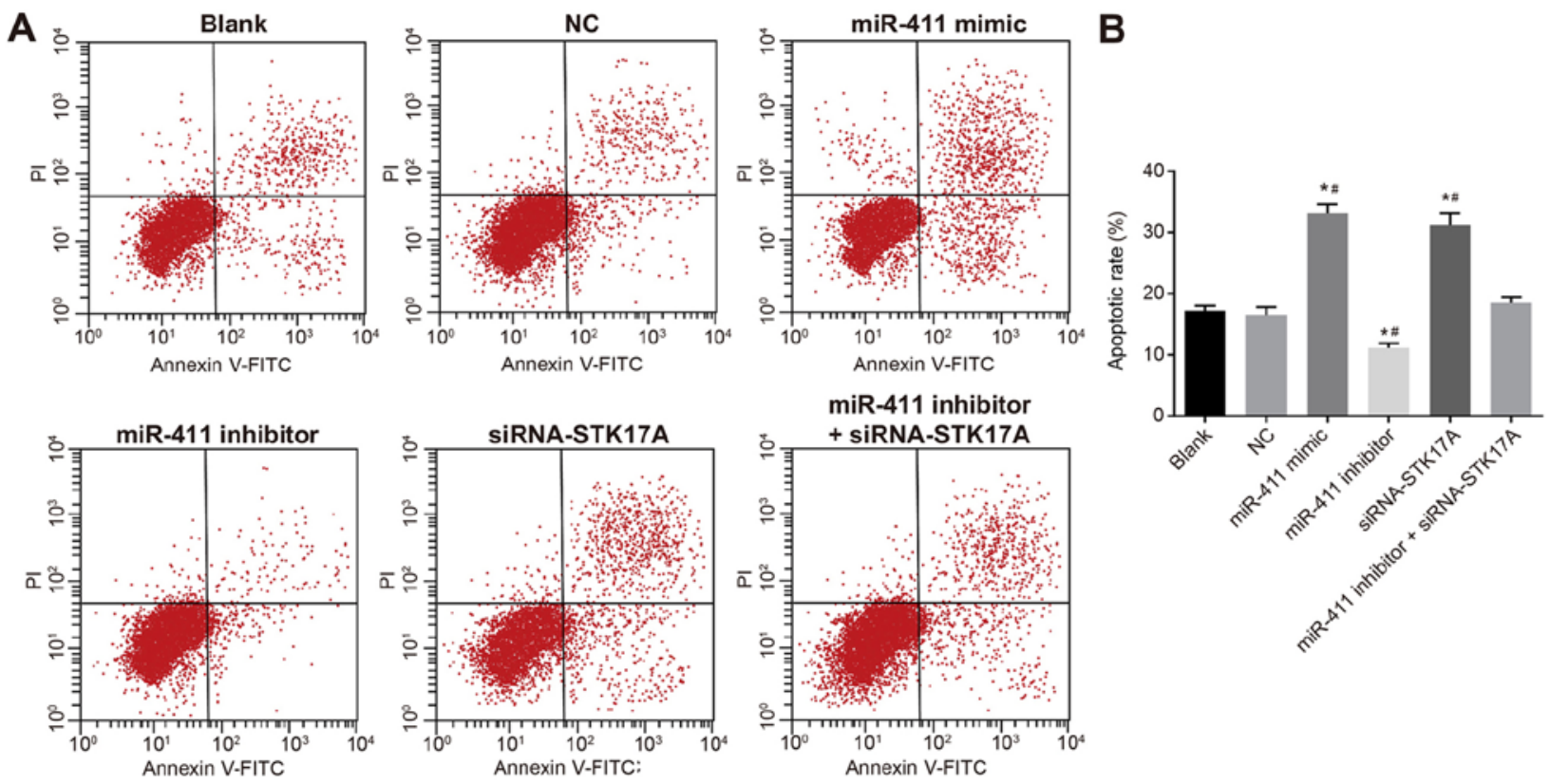

Figure 11. Flow cytometric analysis indicates that miR-411 promotes cervical cancer cell apoptosis through the STK17A-dependent p53 signaling pathway. (A) CaSki cells in the scatter plots, in which the upper left quadrant identifies necrotic cells (Annexin $\mathrm{V}^{-} / \mathrm{PI}^{+}$), the upper right quadrant identifies late apoptotic cells (Annexin $\mathrm{V}^{+} / \mathrm{PI}^{+}$), the lower left quadrant identifies live cells (Annexin $\mathrm{V}^{-} / \mathrm{PI}^{-}$), and the lower right quadrant identifies early apoptotic cells (Annexin $\mathrm{V}^{+} / \mathrm{PI}^{-}$). (B) Percentages of apoptotic cells are indicated in a representative histogram. ${ }^{*} \mathrm{P}<0.05$ vs. NC group; ${ }^{\text {}} \mathrm{P}<0.05$, vs. miR-411 inhibitor + siRNA-STK17A group. The experiment was repeated three times and data were compared by one-way analysis of variance and analyzed by Tukey's post hoc test. NC, negative control; miR-411, microRNA-411; STK17A, serine/threonine kinase 17a; siRNA, small interfering RNA; PI, propidium iodide. 
Yanaihara et al (40), the expression of miRNA was shown to be correlated with the diagnosis and prognosis of cancer, therefore miRNAs can act as biomarkers for cancer. The high expression of miR-411 in patients with lung cancer is found to be correlated with poor prognosis (41). miR-411 and STK17A have been identified as factors influencing ovarian cancer $(19,42)$. The expression of STK17A has been confirmed to affect the prognosis of patients with cervical cancer, and patients with overexpression of STK17A are more likely to have poor outcomes (31).

Additionally, a luciferase reporter gene assay confirmed that STK17A is a target gene of miR-411. In addition, it was detected that the expression levels of p53, p21 ${ }^{\mathrm{WAF} 1}$ and TAp63 were increased by upregulating miR-411 or downregulating STK17A, leading to the suppression of proliferation, migration and invasion, and the promotion of apoptosis in cervical cancer cells. It has been identified that $\mathrm{p} 53$ exhibits increased expression in cancer cells, and the p53 signaling pathway can inhibit the progression of cancer by coordinating transcription programs when activated by diverse stress signals $(43,44)$. STK17A is a novel gene found in p53 and confirmed to be a modulator in various types of cancer, including colon cancer and testicular cancer $(21,45)$. It was previously revealed that miR-411 can function as a factor suppressing the proliferation and invasion but promoting the apoptosis of colorectal cancer cells by directly targeting phosphoinositide-3-kinase regulatory subunit 3 (46). Another study found that increased expression of miR-411 promoted osteosarcoma cell proliferation and migration through inhibiting the expression of metastasis suppressor protein 1 (47). One of the direct and DNA damage-inducible p53 target genes is STK17A, which is involved in cellular processes, and a functional and consensus p53 pathway response element is located upstream of STK17A $(21,48)$. STK17A is regarded as a factor causing apoptosis due to a variety of apoptotic stimuli, including certain drugs, UV light FasL and tumor necrosis factor- $\alpha$, and in a study investigating the correlation between miR-411 and hepatocellular carcinoma cells, miR-411 was confirmed to be involved in cell proliferation $(16,19)$.

In conclusion, the present study provides evidence that miR-411 and its target STK17A are therapeutic biomarkers for efficacy and prognosis in patients with cervical cancer treated with radiotherapy, and that miR-411 downregulating STK17A can inhibit the proliferation, migration and invasion, and promote the apoptosis of cervical cancer cells by activating the p53 signaling pathway. However, the mechanisms of miR-411 in the development and prognosis of cervical cancer require further investigation.

\section{Acknowledgements}

Not applicable.

\section{Funding}

No funding was received.

\section{Availability of data and materials}

The datasets used and/or analyzed during the current study are available from the corresponding author on reasonable request.

\section{Authors' contributions}

WW and CL designed the study. WW performed the experiment and statistical analysis of the results. CL wrote the manuscript.

\section{Ethics approval and consent to participate}

The present study was approved by the Ethics Committee of Jining No. 1 People's Hospital and informed consent was obtained from all patients.

\section{Patient consent for publication}

Not applicable.

\section{Competing interests}

The authors declare that they have no competing interests.

\section{References}

1. Xiong Y, Sun F, Dong P, Watari H, Yue J, Yu MF, Lan CY, Wang Y and Ma ZB: iASPP induces EMT and cisplatin resistance in human cervical cancer through miR-20a-FBXL5/BTG3 signaling. J Exp Clin Cancer Res 36: 48, 2017.

2. Li M, Feng YM and Fang SQ: Overexpression of ezrin and galectin-3 as predictors of poor prognosis of cervical cancer. Braz J Med Biol Res 50: e5356, 2017.

3. Zhang M, Zhang H, Yu Y, Huang H, Li G and Xu C: Synergistic effects of a novel lipid-soluble extract from Pinellia pedatisecta Schott and cisplatin on human cervical carcinoma cell lines through the regulation of DNA damage response signaling pathway. Oncol Lett 13: 2121-2128, 2017.

4. Huang L, Huang Z, Fan Y, He L, Ye M, Shi K, Ji B, Huang J, Wang $\mathrm{Y}$ and Li Q: FOXC1 promotes proliferation and epithelial-mesenchymal transition in cervical carcinoma through the PI3K-AKT signal pathway. Am J Transl Res 9: 1297-1306, 2017.

5. Pedroza-Torres A, López-Urrutia E, García-Castillo V, Jacobo-Herrera N, Herrera LA, Peralta-Zaragoza O López-Camarillo C, De Leon DC, Fernández-Retana J, Cerna-Cortés JF and Pérez-Plasencia C: MicroRNAs in cervical cancer: Evidences for a miRNA profile deregulated by HPV and its impact on radio-resistance. Molecules 19: 6263-6281, 2014.

6. Tang T, Wong HK, Gu W, Yu MY, To KF, Wang CC, Wong YF, Cheung TH, Chung TK and Choy KW: MicroRNA-182 plays an onco-miRNA role in cervical cancer. Gynecol Oncol 129: 199-208, 2013.

7. Chen B, Hou Z, Li C and Tong Y: MiRNA-494 inhibits metastasis of cervical cancer through Pttg1. Tumour Biol 36: 7143-7149, 2015.

8. Cavalleri T, Angelici L, Favero C, Dioni L, Mensi C, Bareggi C, Palleschi A, Rimessi A, Consonni D, Bordini L, et al: Plasmatic extracellular vesicle microRNAs in malignant pleural mesothelioma and asbestos-exposed subjects suggest a 2-miRNA signature as potential biomarker of disease. PLoS One 12: e0176680, 2017.

9. Cho WC: MicroRNAs: Potential biomarkers for cancer diagnosis, prognosis and targets for therapy. Int J Biochem Cell Biol 42: 1273-1281, 2010.

10. Lam CS, Ng L, Chow AK, Wan TM, Yau S, Cheng NS, Wong SK, Man JH, Lo OS, Foo DC, et al: Identification of microRNA $885-5 \mathrm{p}$ as a novel regulator of tumor metastasis by targeting CPEB2 in colorectal cancer. Oncotarget 8: 26858-26870, 2017.

11. Xu Z, Zhou Y, Shi F, Cao Y, Dinh TLA, Wan J and Zhao M: Investigation of differentially-expressed microR NAs and genes in cervical cancer using an integrated bioinformatics analysis. Oncol Lett 13: 2784-2790, 2017.

12. Wang W, Li Y, Liu N, Gao Y and Li L: MiR-23b controls ALDH1A1 expression in cervical cancer stem cells. BMC Cancer 17: 292, 2017. 
13. Harafuji N, Schneiderat P, Walter MC and Chen YW: miR-411 is up-regulated in FSHD myoblasts and suppresses myogenic factors. Orphanet J Rare Dis 8: 55, 2013.

14. Shi X, Xiao X, Yuan N, Zhang S, Yuan F and Wang X: MicroRNA-379 suppresses cervical cancer cell proliferation and invasion by directly targeting V-crk avian sarcoma virus CT10 oncogene homolog-like (CRKL). Oncol Res 26: 987-996, 2018.

15. Sun M, Huang F, Yu D, Zhang Y, Xu H, Zhang L, Li L, Dong L, Guo L and Wang S: Autoregulatory loop between TGF- $\beta 1 / \mathrm{miR}-411-5 \mathrm{p} / \mathrm{SPRY} 4$ and MAPK pathway in rhabdomyosarcoma modulates proliferation and differentiation. Cell Death Dis 6: e1859, 2015.

16. Xia K, Zhang Y, Cao S, Wu Y, Guo W, Yuan W and Zhang S: miR-411 regulated ITCH expression and promoted cell proliferation in human hepatocellular carcinoma cells. Biomed Pharmacother 70: 158-163, 2015.

17. Zhao Z, Qin L and Li S: miR-411 contributes the cell proliferation of lung cancer by targeting FOXO1. Tumour Biol 37: 5551-5560, 2016.

18. Zhang X, Zhang M, Cheng J, Lv Z, Wang F and Cai Z: MiR-411 functions as a tumor suppressor in renal cell cancer. Int J Biol Markers 32: e454-e460, 2017.

19. Gao J, Liu D, Li J, Song Q and Wang Q: Effect of STK17A on the sensitivity of ovarian cancer cells to paclitaxel and carboplatin. Oncol Lett 12: 1107-1112, 2016.

20. Mao P, Hever-Jardine MP, Rahme GJ, Yang E, Tam J, Kodali A Biswal B, Fadul CE, Gaur A, Israel MA and Spinella MJ: Serine/threonine kinase $17 \mathrm{~A}$ is a novel candidate for therapeutic targeting in glioblastoma. PLoS One 8: e81803, 2013.

21. Mao P, Hever MP, Niemaszyk LM, Haghkerdar JM, Yanco EG Desai D, Beyrouthy MJ, Kerley-Hamilton JS, Freemantle SJ and Spinella MJ: Serine/threonine kinase 17A is a novel p53 target gene and modulator of cisplatin toxicity and reactive oxygen species in testicular cancer cells. J Biol Chem 286: 19381-19391, 2011.

22. Prives C and Hall PA: The p53 pathway. J Pathol 187: 112-126, 1999.

23. Zhang S, Zhou L, Hong B, van den Heuvel AP, Prabhu VV, Warfel NA, Kline CL, Dicker DT, Kopelovich L and El-Deiry WS Small-molecule NSC59984 restores p53 pathway signaling and antitumor effects against colorectal cancer via p73 activation and degradation of mutant p53. Cancer Res 75: 3842-3852, 2015.

24. Muthusami S, Prabakaran DS, An Z, Yu JR and Park WY: EGCG suppresses Fused Toes Homolog protein through p53 in cervical cancer cells. Mol Biol Rep 40: 5587-5596, 2013.

25. Wu PP, Chung HW, Liu KC, Wu RS, Yang JS, Tang NY, Lo C, Hsia TC, Yu CC, Chueh FS, et al: Diallyl sulfide induces cell cycle arrest and apoptosis in HeLa human cervical cancer cells through the p53, caspase- and mitochondria-dependent pathways Int J Oncol 38: 1605-1613, 2011.

26. Au Yeung CL, Tsang TY, Yau PL and Kwok TT: Human papillomavirus type 16 E6 induces cervical cancer cell migration through the p53/microRNA-23b/urokinase-type plasminogen activator pathway. Oncogene 30: 2401-2410, 2011.

27. Waggoner SE: Cervical cancer. Lancet 361: 2217-2225, 2003.

28. Meva J, Chaudhary RK, Bhaduri D, Bhatia M, Hatti S and Ba R: Lacunae in International Federation of Gynecology and Obstetrics (FIGO) classification for cervical carcinoma: Observational study using TNM classification as comparator. Int J Gynecol Cancer 23: 1071-1077, 2013.

29. Eisenhauer EA, Therasse P, Bogaerts J, Schwartz LH, Sargent D, Ford R, Dancey J, Arbuck S, Gwyther S, Mooney M, et al: New response evaluation criteria in solid tumours: Revised RECIST guideline (version 1.1). Eur J Cancer 45: 228-247, 2009.

30. Livak KJ and Schmittgen TD: Analysis of relative gene expression data using real-time quantitative PCR and the 2(-Delta Delta C(T)) method. Methods 25: 402-408, 2001

31. Thomas A, Mahantshetty U, Kannan S, Deodhar K, Shrivastava SK, Kumar-Sinha C and Mulherkar R: Expression profiling of cervical cancers in Indian women at different stages to identify gene signatures during progression of the disease. Cancer Med 2: 836-848, 2013
32. Zhao S, Yao D, Chen J and Ding N: Circulating miRNA-20a and miRNA-203 for screening lymph node metastasis in early stage cervical cancer. Genet Test Mol Biomarkers 17: 631-636, 2013.

33. Guo L, Yuan J, Xie N, Wu H, Chen W, Song S and Wang X: miRNA-411 acts as a potential tumor suppressor miRNA via the downregulation of specificity protein 1 in breast cancer. Mol Med Rep 14: 2975-2982, 2016.

34. Wang G, Zhang Y, Zhao X, Meng C, Ma L and Kong Y: MicroRNA-411 inhibited matrix metalloproteinase 13 expression in human chondrocytes. Am J Transl Res 7: 2000-2006, 2015.

35. Ozeki M, Salah A, Aini W, Tamaki K, Haga H and MiyagawaHayashino A: Abnormal localization of STK17A in Bile Canaliculi in liver allografts: An early sign of chronic rejection. PLoS One 10: $\mathrm{e} 0136381,2015$.

36. Park Y, Kim W, Lee JM, Park J, Cho JK, Pang K, Lee J, Kim D, Park SW, Yang KM and Kim SJ: Cytoplasmic DRAK1 overexpressed in head and neck cancers inhibits TGF- $\beta 1$ tumor suppressor activity by binding to Smad 3 to interrupt its complex formation with Smad4. Oncogene 34: 5037-5045, 2015.

37. Liu Y, Li L, Liu Y, Geng P, Li G, Yang Y and Song H: RECK inhibits cervical cancer cell migration and invasion by promoting p53 signaling pathway. J Cell Biochem 119: 3058-3066, 2017.

38. Shi C and Zhang Z: MicroRNA-362 is downregulated in cervical cancer and inhibits cell proliferation, migration and invasion by directly targeting SIX1. Oncol Rep 37: 501-509, 2017.

39. Lever J, Gakkhar S, Gottlieb M, Rashnavadi T, Lin S, Siu C, Smith M, Jones M, Krzywinski M and Jones SJM and Wren J: A collaborative filtering based approach to biomedical knowledge discovery. Bioinformatics 34: 652-659, 2017.

40. Yanaihara N, Caplen N, Bowman E, Seike M, Kumamoto K, Yi M, Stephens RM, Okamoto A, Yokota J, Tanaka T, et al: Unique microRNA molecular profiles in lung cancer diagnosis and prognosis. Cancer Cell 9: 189-198, 2006.

41. Nadal E, Zhong J, Lin J, Reddy RM, Ramnath N, Orringer MB, Chang AC, Beer DG and Chen G: A MicroRNA cluster at 14q32 drives aggressive lung adenocarcinoma. Clin Cancer Res 20: 3107-3117, 2014.

42. Kim YW, Kim EY, Jeon D, Liu JL, Kim HS, Choi JW and Ahn WS: Differential microRNA expression signatures and cell type-specific association with Taxol resistance in ovarian cancer cells. Drug Des Devel Ther 8: 293-314, 2014.

43. Brucker J, Mayer C, Gebauer G, Mallmann P, Belau AK, Schneeweiss A, Sohn C and Eichbaum M: Non-pegylated liposomal doxorubicin for patients with recurrent ovarian cancer: A multicentric phase II trial. Oncol Lett 12: 1211-1215, 2016.

44. Muller PA and Vousden KH: p53 mutations in cancer. Nat Cell Biol 15: 2-8, 2013

45. Tang H, Liu YJ, Liu M and Li X: Establishment and gene analysis of an oxaliplatin-resistant colon cancer cell line THC8307/ L-OHP. Anticancer Drugs 18: 633-639, 2007.

46. Zhao J, Xu J and Zhang R: MicroRNA-411 inhibits malignant biological behaviours of colorectal cancer cells by directly targeting PIK3R3. Oncol Rep 39: 633-642, 2018.

47. Xu N, Yang W, Liu Y, Yan F and Yu Z: MicroRNA-411 promoted the osteosarcoma progression by suppressing MTSS1 expression. Environ Sci Pollut Res Int 25: 12064-12071,2018.

48. Cekirge HS, Peynircioglu B and Saatci I: Endovascular treatment of an 'anterior cerebral artery' aneurysm in a patient with 'embryonic unfused middle cerebral artery' anomaly: A case report. Neuroradiology 47: 690-694, 2005.

This work is licensed under a Creative Commons Attribution-NonCommercial-NoDerivatives 4.0 International (CC BY-NC-ND 4.0) License. 